\title{
6 Syntaktische Aspekte
}

Das syntaktische Verhalten von FVG wird herkömmlicherweise als partiell irregulär und konstruktionsspezifisch beschrieben. Als typisch für FVG werden u. a. Restriktionen bei der Modifizierbarkeit durch ein Adjektivattribut bzw. einen Relativsatz, bei der pronominalen Wiederaufnahme, bei der Pluralisierbarkeit sowie bei der Artikelwahl angesehen (Heidolph/Flämig/Motsch 1981: 431-442; Helbig/Buscha 2001: 88-92; Zifonun/Hoffmann/Strecker 1997: 53f.; Hentschel/ Weydt 2003: 86; Hyvärinen 2003: 748; Storrer 2006: 152f.; zum Artikelgebrauch besonders Eisenberg 2006b: 314f. und Fuhrhop 2007: 275). Wie hoch die Konstruktionsspezifik dieser Restriktionen veranschlagt wird, belegen auch die in Kapitel 2 diskutierten Versuche, die Klasse der FVG über einzelne dieser Restriktionen zu definieren. Auch wenn, wie in dem genannten Kapitel dargelegt, etwa die Beschränkungen bei der pronominalen Wiederaufnahme und der Pluralisierbarkeit keine geeigneten Definitionskriterien für eine Klasse FVG liefern, sind damit gleichwohl auffallende Charakteristika derartiger Konstruktionen gegeben, die einer näheren Betrachtung lohnen.

Wenn im vorangegangenen Kapitel die Frage nach Regularität bzw. Irregularität der FVG im Mittelpunkt stand, so soll im folgenden Kapitel auch die Syntax von FVG unter diesem Blickwinkel behandelt werden. Dabei werden die folgenden Phänomene erörtert: Zunächst ist die zentrale Frage zu klären, wie die Argumentstruktur von FVG beschaffen ist. Sind die Argumente im Satz auf das FV, das gesamte FVG oder auf das Nomen im FVG zu beziehen? Einen weiteren Komplex, der mit der Frage nach der Argumentstruktur eng zusammenhängt, bilden die topologischen Eigenschaften von FVG. Auch hier gilt es zu untersuchen, ob das entsprechende Verhalten von FVG auf der Grundlage der allgemeinen Regeln zu beschreiben ist oder ob konstruktionsspezifische Regularitäten anzunehmen sind. Im Anschluss daran sind der Artikelgebrauch, die Modifizierbarkeit durch Attribute bzw. Relativsätze sowie die Pluralisierbarkeit des Nomens zu thematisieren. Zuletzt soll auch zu der in der Forschung gelegentlich erörterten Frage Stellung genommen werden, ob bei FVG sog. Objektinkorporation vorliegt, wie sie für Verbindungen wie Klavier spielen oder Auto fahren angenommen wird.

\subsection{Argumentzuweisung}

In der Forschung wird überwiegend davon ausgegangen, dass das FVG als Ganzes die Valenz trägt, die Argumente im Satz also nicht auf das Verb, sondern auf

2 Open Access. ( 2021 Volker Harm, publiziert von De Gruyter. (c) BY Dieses Werk ist lizenziert unter der Creative Commons Attribution-NonCommercial-NoDerivatives 4.0 Lizenz.

https://doi.org/10.1515/9783110661255-006 
die Verbindung von Nomen und Verb zu beziehen sind (s. Helbig/Buscha 1993: 92; Hentschel/Weydt 2003: 85f.; Heine 2006: 74${ }^{141}$ ). FVG werden damit hinsichtlich ihrer Valenz wie verbale Phraseologismen behandelt (Wotjak/Heine 2007: 50). Zum Teil wird allerdings auch die gegenteilige Position vertreten. So ist van Pottelberge der Ansicht, dass ,die syntaktischen Valenzverhältnisse in Funktionsverbgefügen offenkundig nicht von der normalen deutschen Syntax abweichen“ (2001: 55). Er macht sich dabei ausdrücklich die Auffassung von S. Lehmann (1983: 43) zu eigen, der zufolge der Stellenplan des Satzes vom FV und nicht etwa von der gesamten Nomen-Verb-Verbindung festgelegt werde.

Vertreter der Auffassung, dass Nomen und Verb eine semantische und syntaktische Einheit, ein komplexes Prädikat bilden, das als Ganzes die Argumentstellen vergibt, gehen gleichwohl meist davon aus, dass die Argumentvergabe in erster Linie durch das Nomen gesteuert wird:

Entsprechend der Tatsache, dass innerhalb des FVG nicht das FV, sondern das SF [Substantiv im FVG, V. H.] die hauptsächliche lexikalische Bedeutung trägt, ist das SF ein Hauptvalenzträger im Satz. Weitere Objekte und Adverbialien im Satz hängen nicht direkt vom FV, sondern vom SF und erst über dieses SF von der Gesamtheit des FVG ab.

(Helbig 1979: 277)

Diese Position wird häufig auch in der Weise ausformuliert, dass hinsichtlich der Valenzvergabe eine Funktionsverteilung zwischen Nomen und Verb bestehe. Das Verb stellt hierbei lediglich die syntaktischen Leerstellen (quantitative Valenz) bereit, während das Nomen die semantische Füllung (qualitative Valenz) dieser Positionen determiniert (Heidloph/Flämig/Motsch 1981: 433; Rösch 1993: 22; 1994: 92f.). ${ }^{142}$

Grimshaw/Mester (1988) explizieren diese Annahme im theoretischen Rahmen des Government-and-Binding-Modells. Für die Verbindungen mit dem japanischen Verb suru ,tun', die den FVG des Deutschen vergleichbar sind, wird hier ein ,argument transfer“ vom Nomen an das Verb postuliert. Das FV (,light verb“) weist dieser Hypothese zufolge allein einen Kasus, jedoch keine semantische Rolle zu; es absorbiert somit das $\theta$-Muster des Nomens. Die Kasuszuweisung ohne

141 Vgl. hierzu auch den nützlichen Forschungsüberblick bei Heine (2006: 36-43).

142 Ein ähnlicher Erklärungsansatz für englische Fügungen wie to put the blame on, to take a walk usw. findet sich auch bei Jackendoff (1974: 490): „the main verb serves as a sort of syntactic skeleton onto which the syntactically deficient nominal can be grafted to produce a fully interpretable semantic function“; vgl. auch Culicover/Jackendoff (2005: 222f.). 
Vergabe einer Rolle wird dabei als definierend für „light verbs“ erachtet (Grimshaw/Mester 1988: 205). Die Verbindung jap. keikoku „Warnung“ + suru in (1c) ist dieser These zufolge als Resultat eines Transfers der Argumente von (1a) an (1b) $\mathrm{zu}$ beschreiben.
a. keikoku (Agent, Goal, Theme)
b. $\operatorname{suru}(\quad)<\mathrm{acc}>$
c. keikoku ( ) +suru (Agent, Goal, Theme) <acc>

Grimshaw/Mester (1988: 212)

Grimshaw/Mester sehen trotz einiger Unterschiede im Detail grundsätzliche Gemeinsamkeit zwischen den jap. suru-Konstruktionen und den englischen lightverb-Verbindungen wie give someone a kick, put the blame on something oder take $a$ walk. Auch für diese Fügungen gelte: „The Verb provides the sub-categorization/case structure for the clause level and has an incomplete argument structure, whereas the Noun has a complete one. Arguments of the Noun transfer to the Verb, as for suru“ (Grimshaw/Mester 1988: 230).

Van Pottelberge merkt zu der These einer solchen Funktionsverteilung zwischen Nomen und Verb an, dass diese keine Besonderheit von FVG oder vergleichbarer Verbindungen anderer Sprachen darstelle. Vielmehr sei allgemein festzustellen, dass die Valenz nicht nur vom Verb allein, sondern auch vom Nomen bestimmt werden könne. FVG verhalten sich also auch in dieser Hinsicht, so van Pottelberges Grundthese, syntaktisch vollkommen unauffällig. Um zu zeigen, wie das Nomen die Valenz beeinflusse, führt van Pottelberge (2001: 60) das Beispielpaar in (2) an.

a. Er gibt seinem Nachbarn ein Geschenk.

b. Er gibt seinen Worten Nachdruck.

Hier sind es nach van Pottelberges Ansicht die Nomina Geschenk bzw. Nachdruck, die bestimmten, dass im ersten Fall ein belebtes Dativobjekt (Nachbarn), im zweiten dagegen ein unbelebtes Dativobjekt (Worten) vorliegt. Die Festlegung, ob das Verb geben ein belebtes oder unbelebtes Dativobjekt hat, werde damit durch das Nomen getroffen. Die Kontrastierung von (2a) und (2b) muss jedoch insofern als wenig aussagekräftig angesehen werden, als die Besetzung der Leerstellen in (2b) alles andere als frei ist. Vielmehr handelt es sich bei (einer Sache) Nachdruck geben um eine Kollokation, da das zu Nachdruck gehörige Verb hier nur geben oder verleihen sein kann (zum Begriff ,Kollokation‘ s. auch Kapitel 
4.2.2). ${ }^{143}$ Nur bei jmdm. ein Geschenk geben liegt eine freie syntaktische Kombination vor. Hier verhält es sich indes eher so, dass das Verb geben, das hier in der Transferlesart gebraucht wird, die semantische Klasse des Dativobjekts determiniert - das Verb geben fordert schlicht einen Rezipienten, und dieser ist prinzipiell belebt (vgl. Primus 2012: 44f.), ganz unabhängig davon, welcher semantischen Klasse das Patiens-Argument angehört.

Ein Nachteil des Ansatzes von Grimshaw/Mester besteht freilich darin, dass im Deutschen jeweils eigene Lexikoneinträge für die ,light verbs‘ bzw. FV zu postulieren sind. Für Verben wie geben, nehmen, bringen, kommen, stellen, haben etc. wären dann mindestens je zwei Einträge - für das FV und die Vollverbvariante - vorauszusetzen, deren Verhältnis zueinander zudem noch zu klären wäre. Wenn für das Lexikon prinzipiell die Forderung nach Ökonomie der Beschreibung gelten soll, sind solche Doubletten theoretisch unerwünscht. Trotz möglicher Kritik an der Hypothese der Funktionsaufteilung von Nomen und Verb ${ }^{144}$ bleibt die - letztlich auch durch van Pottelberge nicht bestrittene - Intuition, dass die Argumente des Nomens im FVG zugleich auch die Argumente des Verbs sind, attraktiv. Wie dies genau modelliert werden kann, soll in Kapitel 8 gezeigt werden.

Im Zusammenhang mit der Frage nach der Argumentzuweisung bei FVG werden besonders auch die FVG diskutiert, an die optional eine PP angeschlossen werden kann, vgl. die Beispiele in (3).
a. Wir nehmen Einfluss auf seine Entwicklung.
b. Die Kinder haben Angst vor der Fahrt.
c. Sie gerät in Abhängigkeit von ihren Eltern.

(Helbig/Buscha (2001: 92)

Van Pottelberge ist der Auffassung, dass die PPs in den genannten Beispielen „ganz einfach auf die Valenzeigenschaften des Substantivs zurückzuführen sind, denn die Substantive Einfluss, Angst und Abhängigkeit können auch außerhalb der Funktionsverbgefüge mittels der genannten Präpositionen problemlos Präpositionalphrasen bilden“ (2001: 51). Demgegenüber sehen Helbig/Buscha (2001: 92) in der Voranstellbarkeit der Präpositionalphrasen ein Argument dafür, dass es sich um Satzglieder zu einem komplexen Verbalausdruck und nicht um präpositionale Attribute zum FVG-Nomen handelt. Zum Beleg führen sie die Sätze in

143 Auch bei weiteren Beispielen, die van Pottelberge (2001: 60) zum Beleg seiner These anführt - jmdn. vor Schwierigkeiten stellen und sich Zeit nehmen -, sind Kollokationen im Spiel. $144 \mathrm{Zu}$ weiteren Kritikpunkten, vor allem zur Analyse von japan. suru, vgl. Butt (1995: 204f.). 
(4) an, bei denen allerdings nur in (4a) und (4b), nicht in (4c) eine zweifelsfrei vorfeldfähige PP gegeben ist.

(4) a. [Auf seine Entwicklung] nehmen wir Einfluss.

b. [Vor der Fahrt] haben die Kinder Angst.

c. ?[In Abhängigkeit] gerät sie von ihren Eltern.

Van Pottelberge (2001: 53) vertritt dagegen explizit die Auffassung, dass die Präpositionalphrasen in (4) keine Satzglieder sind, da die Vorfeldfähigkeit von PP für FVG nicht spezifisch sei. In der Tat ist die sog. PP-Extraktion kein Alleinstellungsmerkmal von FVG, sondern stellt eine weiter verbreitete Möglichkeit dar, wie der bekannte Beispieltyp (5) zeigt (dazu ausführlich Abschnitt 6.2.2).

a. Ich habe [ein Buch [über Syntax]] gelesen.

b. [Über Syntax $]_{\mathrm{i}}$ habe ich [ein Buch $\mathrm{t}_{\mathrm{i}}$ ] gelesen].

Van Pottelberges Einwand, es handele sich hier um ein allgemeines, nicht für FVG kennzeichnendes Phänomen, verfehlt allerdings insofern sein Ziel, als die Frage, ob Extraktion nur bei FVG oder auch andernorts auftritt, keine Relevanz für die Entscheidung besitzt, ob einer PP Satzglied- oder Attributstatus zukommt. Wenn man die Extraktionsfähigkeit als heuristisches Mittel zur Bestimmung des Satzgliedstatus einer Konstituente anerkennt (Gallmann/Sitta 1992: 153; Dürscheid 2010: 48), dann gilt dieses Mittel generell und nicht nur in Bezug auf bestimmte Konstruktionen. Daher wird auch bei Helbig/Buscha (2001: 92) mit gutem Grund keine Exklusivität dieses Phänomens für FVG behauptet.

Bedenkenswerte Argumente für eine Analyse der PP als Nominalattribut und gegen eine Analyse als Komplement zu einem komplexen Prädikat hat allerdings Schmellentin (2006) vorgebracht. Ihre Überlegungen basieren auf der Beobachtung von Steinitz (1989: 210), der zufolge PP-Komplemente bei Endstellung des Verbs grundsätzlich dem Verb adjazent sein müssen. Scrambling der PP sei hier deshalb nicht möglich, vgl. (6).

(6) a. Mario hat vorher [die Bücher] ins Regal gestellt.

b. *Mario hat vorher [ins Regal] die Bücher gestellt.

(vgl. Schmellentin 2006: 47)

Bei FVG kann die PP allerdings aus der Position unmittelbar vor der rechten Peripherie herausgescrambelt werden, wie (7) zeigt. 
(7) a. Eva hat durchaus Verständnis [für Otto] gezeigt.

b. Eva hat [für Otto] durchaus Verständnis gezeigt.

(vgl. Schmellentin 2006: 47)

Daraus wäre der Schluss zu ziehen, dass die PP [vor Hunden] kein Komplement sein kann, da andernfalls ein Verstoß gegen die von Steinitz aufgestellte Regel vorläge. Die PP müsse daher, so Schmellentin (2006: 47), ,in die DP eingebettet sein, denn ansonsten wäre [...] das deverbale Nomen Verständnis nicht adjazent zum Verb“.

Schmellentins Argumentation ist schlüssig, sie setzt freilich voraus, dass man die zugrunde gelegte Hypothese von Steinitz akzeptiert. Diese wirft insofern Fragen auf, als die Regel, dass PPs fest dem Bereich an der rechten Peripherie angehören, nur für lokale und direktionale PPs gilt, wie sie in dem Musterbeispiel (7) vorliegen, während bei nicht-lokalen bzw. nicht-direktionalen PPs gerade mit für Scrambling durchaus möglich ist, wie (8) nahelegt.

a. Eva hat doch das Examen [für ihre Eltern] gemacht.

b. Eva hat doch [für ihre Eltern] das Examen gemacht.

Auch wenn man Steinitz' Adjazenzregel trotz offener Fragen eine hohe Erklärungskraft für die freie Syntax zubilligen darf, so fallen PPs, die sich auf verbale Idiome beziehen, gänzlich aus dem Rahmen, der durch diese Regel absteckt ist (freilich haben weder Steinitz noch Schmellentin sich mit PPs in idiomatischen VPs auseinandergesetzt). Bei idiomatischen VPs wie in (9) ist eine Adjazenz der PP zum Verb jedenfalls nicht gegeben.

a. Eva hat einen Narren [an Otto] gefressen.

b. Eva hat [an Otto] einen Narren gefressen.

Die Bewegbarkeit der PP beim FVG in (7) ist daher nicht zwingend als Argument gegen deren Komplementstatus bzw. für NP-Einbettung zu sehen; eher ist damit ein Argument dafür gegeben, dass das FVG in (7) nicht anders zu bewerten ist als der Phraseologismus in (9). Der Verstoß gegen die Adjazenzregel wäre kein Beweis gegen den Komplementstatus der PP, sondern eher ein Indiz dafür, dass FVG sich in dieser Hinsicht wie Phraseologismen verhalten.

Eine Beobachtung, die klar gegen die von Schmellentin (2006: 47) und van Pottelberge (2001: 51) bevorzugte Analyse der PP als Nominalattribut spricht, ergibt sich allerdings aus den in Kapitel 5.3.3 gewonnenen Erkenntnissen zur Akzeptabilität bestimmter Nomina in FVG. So konnte gezeigt werden, dass Nomina, 
die keine präpositionale, sondern lediglich eine genitivische Anschlussmöglichkeit besitzen, kein FVG bilden können, obwohl sie von ihrer Bedeutung her durchaus passend erscheinen. Dies konnte am Akzeptabilitätsunterschied zwischen Zustimmung geben und *Befürwortung geben demonstriert werden: Zustimmung ist mit $z$-PP erweiterbar, Befürwortung erlaubt nur den Anschluss eines genitivischen Attributs. Dieser Befund ist am besten erklärbar, wenn man annimmt, dass das jeweilige Argument als Komplement des gesamten FVG gilt, da Komplemente im Genitiv nur auf sehr wenige Ausnahmefälle beschränkt sind (sich einer Sache annehmen usw.). Ginge man davon aus, dass das Argument bei FVG Attribut zu einer NP wäre, so müsste z. B. ^Befürwortung des Vorschlags geben völlig unbedenklich sein. Da dies nicht der Fall ist, scheidet eine solche Analyse aus. Dies spricht - ex negativo - dann auch für die Analyse der einschlägigen PPs als Komplemente des zum gesamten FVG. Dessen interne Valenzverhältnisse werden, wie eingangs gezeigt, immer noch am besten durch die These einer Argumentvererbung vom Nomen an das Funktionsverb erklärt.

\subsection{Topologische Eigenschaften}

\subsubsection{PP-Extraktion}

\subsubsection{Probleme der Forschung}

Als syntaktische Faustregel gilt, dass eine Konstituente, die von einer anderen Konstituente dominiert wird - die also, traditionell gesprochen, kein Satzglied darstellt -, im Regelfall nicht bewegt werden kann. Diese starke Beschränkung ist von Bach/Horn (1976: 280) als sog. „NP-Constraint“ formuliert worden: „No constituent which is dominated by NP can be moved or deleted from that NP by a transformational rule“. Im GB-Modell ist diese Beschränkung insofern berücksichtigt, als Topikalisierung („Fronting“) nur maximale Projektionen betreffen kann (Chomsky 1986: 4; vgl. de Kuthy 2002: 145). Die Bewegung einer PP, die von einer NP dominiert wird, ist daher im Prinzip ungrammatisch:

a. Bill hat [ein Buch [über Syntax]] verbrannt.

b. *[Über Syntax $]_{\mathrm{i}}$ hat Bill [ein Buch $\mathrm{t}_{\mathrm{i}}$ ] verbrannt.

Vor diesem Hintergrund stellen allerdings Äußerungen wie die in (11) einen Verstoß gegen den NP-Constraint dar, da hier offenbar doch eine PP aus einer übergeordneten NP herausbewegt wird. 
(11) a. Bill hat [ein Buch [über Syntax]] gelesen.

b. [Über Syntax $]_{i}$ hat Bill [ein Buch $t_{i}$ ] gelesen.

Das in (11) vorliegende Stellungsphänomen wird in der Forschungsliteratur auch als „PP-Extraktion“ (Pafel 1993: 119, Winhart 2005: 114, 120) oder „NP-PP-Split“ (de Kuthy 2001: 31; 2002: 5) bezeichnet. FVG sind in diesem Zusammenhang von besonderem Interesse, weil bei FVG, deren NP eine PP dominieren kann, eine Extraktion der PP sehr leicht möglich zu sein scheint (Winhart 2005: 114f.).

(12) a. [Auf diese Frage $]_{i}$ gab er [keine Antwort $\left.t_{i}\right]_{\text {. }}$

b. [Vor Hunden] $]_{i}$ hat der Junge [Angst $t_{i}$.

c. [An diesem Studenten $]_{i}$ hat der Professor [Kritik $t_{i}$ geübt.

d. [Über Syntax] $]_{i}$ machte sie [eine interessante Beobachtung $\mathrm{t}_{\mathrm{i}}$ ]

e. [Zur Syntax $]_{i}$ stellte sie [eine Frage $t_{i}$.

f. [Zur Währungsunion] $]_{i}$ machte sie [eine Bemerkung $t_{i}$ ].

Wenn Winhart (2005: 114) und andere mit Recht „die gute Extrahierbarkeit“ von PPs aus FVG konstatieren, so ist allerdings anzumerken, dass es durchaus eine wenn auch kleine - Anzahl von FVG gibt, die offenbar keine Extraktion der PP erlauben.

(13) a. 'In die Luft machte er einen Sprung.

b. 'In die falsche Richtung machte er eine Bewegung.

c. *Auf eine Verbesserung meiner Lage habe ich Hoffnung.

Es ist also einerseits zu fragen, weshalb Extraktion bei FVG grundsätzlich gut funktioniert, andererseits ist auch zu klären, weshalb Fügungen wie die in (13) eine Ausnahme darstellen. Beide Fragen können allerdings nur vor dem Hintergrund einer übergreifenden Theorie der Extraktion befriedigend beantwortet werden. Eine mehr oder weniger breit anerkannte Modellierung des Phänomens, die auch auf FVG übertragbar wäre, ist indes bisher nicht vorgelegt worden. Als ein Grund hierfür ist an erster Stelle die problematische empirische Basis zu nen- 
nen. Die Akzeptabilitätsurteile, auf denen die Erklärungsansätze fußen, schwanken nicht selten von Autor zu Autor. ${ }^{145}$ Dies hängt offenbar mit der großen Bedeutung des vorangehenden Kontextes für die Akzeptabilität einer Extraktion zusammen: Ob eine Extraktion gut oder schlecht bewertet wird, richtet sich oftmals danach, ob ein Kontext konstruiert werden kann, der die entsprechende Äußerung akzeptabel erscheinen lässt (Fanselow 1991: 184f.; de Kuthy 2002: 47). Dies zeigt de Kuthy (2002) sehr anschaulich am Beispiel der Extraktion in (14a). Diese ist für sich genommen schlecht zu bewerten; durch Einbettung in einen Kontext wie in (14b) indes kann sie deutlich an Akzeptabilität gewinnen.

(14) a. *Über Semantik hat er ein Buch geklaut.

b. Gestern wurde in der Bibliothek eine Anzahl von Linguistikbüchern geklaut. Vor allem Syntaxbücher verschwanden dabei. Über Semantik wurde jedoch nur ein einziges Buch geklaut.

(de Kuthy 2002: 3; vgl. de Kuthy/Meurers 2001: 197)

Dies weist, wie noch zu zeigen sein wird, auf eine bedeutende Rolle der Informationsstruktur für dieses Stellungsphänomen hin (de Kuthy 2002: 3; Schmellentin 2006: 127-145; dazu s. u.). Informationsstrukturelle Gegebenheiten können in großen Textsammlungen freilich nur mit vergleichsweise hohem Aufwand systematisch untersucht werden.

$\mathrm{Zu}$ diesen empirischen Schwierigkeiten der Datenerhebung und -beurteilung kommt hinzu, dass Extraktion auch theoretisch umstritten ist. Im Wesentlichen stehen hier zwei Typen von Erklärungen einander gegenüber (de Kuthy/Meurers 2001: 144-157): Reanalyse und „Remnant Movement“. Eine Reanalysehypothese für PP-Extraktion hat Fanselow (1987: 61) mit der Regel (15) formuliert.

$$
[\mathrm{vp}[\mathrm{NP} \operatorname{det} \mathrm{N} P \mathrm{PP}] \mathrm{V}] \rightarrow[\mathrm{vr}[\mathrm{NP} \operatorname{det} \mathrm{N}] \mathrm{PP} \mathrm{V}]
$$

145 Dies stellt bereits Winhart (2005: 115) fest: „Der Bereich der NP-PP-Aufspaltung [...] zeichnet sich nicht nur durch eine besondere Datenfülle, sondern auch durch sehr unterschiedliche Datenbeurteilung aus“. Problematisch an den Grammatikalitätsurteilen der Forschungsliteratur ist zum Teil auch, dass nicht gefragt wird, ob nicht bereits der entsprechende Satz ohne Extraktion ungrammatisch ist. Wenn Winhart (2005: 127) etwa den Satz ${ }^{\star}$ Nach der Uhrzeit habe ich eine Frage gestellt diskutiert und diesen als ungrammatisch bewertet, geschieht dies nicht vor dem Hintergrund der Frage, ob nicht bereits der Satz Ich habe eine Frage nach der Uhrzeit gestellt äußerst problematisch ist. 
Dieser Regel zufolge ist hier eine Topikalisierung ohne Verstoß gegen den NPConstraint möglich, da die NP die PP nach Vollzug der Reanalyse nicht länger dominiert; vielmehr treten NP und PP als Schwesterkonstituenten innerhalb der VP auf (s. auch de Kuthy 2001: 27). Dementsprechend wäre der Satz Bill las ein Buch über Chomsky wie in (16) zu reanalysieren:

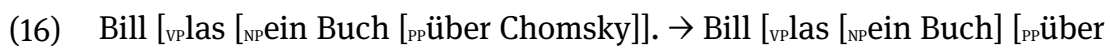
Chomsky]].

Als Bedingung für eine Reanalyse im Sinne Fanselows hat Grewendorf (1989: 47) eine thematische Restrukturierung postuliert, in deren Gefolge die PP den Status eines V-Komplements erhält. Im Zuge einer solchen Reorganisation bilden Verb und NP einen komplexen Verbalausdruck, der die PP theta-markiert (ebd. 45, 47): „A second reanalysis process must be assumed which not only ,breaks up“ the complex NP (as Fanselow suggests), but forms a complex verbal expression with the head NP and the verb“ (ebd. 45); vgl. dazu (17).

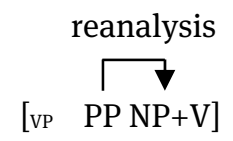

(Grewendorf 1989: 45)

Einer anderen Forschungstradition folgend ist PP-Extraktion als Fall von sog. „Remnant Movement“ zu beschreiben (grundlegend den Besten/Webelhuth 1990; G. Müller 1996; einführend Grewendorf 2015). In diesem Fall liegt eine Abfolge von zwei Prozessen vor: Zunächst wird die NP per Scrambling aus der Phrase herausbewegt und in einem zweiten Schritt der Rest, d. h. die PP zusammen mit der Spur, welche die NP hinterlassen hat, topikalisiert, wie der Übergang von (18a) zu (18b) und (18c) zeigt.

(18) a. Bill las [ein Buch [ppüber Chomsky]]

b. Bill las [ein Buch $]_{i}\left[t_{i}\right.$ über Chomsky].

c. [ $\mathrm{t}_{\mathrm{i}}$ über Chomsky $]_{\mathrm{j}}$ las Bill [ein Buch $]_{\mathrm{i}} \mathrm{t}_{\mathrm{j}}$

Da hier im Prinzip eine - wenn auch resthafte - NP bewegt wird, muss auch kein Verstoß gegen den NP-Constraint angenommen werden.

Die Entscheidung, welchem der beiden Ansätze der Vorzug zu geben ist, hängt zunächst von allgemeinen theoretischen Überlegungen und Präferenzen 
ab. G. Müller (1998: 11-12) hat dargelegt, dass die Reanalysehypothese im Rahmen des GB-Modells bzw. des Minimalismus nur schwer zu formulieren sei, während die Annahme von Remnant-Movement in diesem Zusammenhang weniger Probleme bereite. Auf der anderen Seite haben de Kuthy (2001: 60ff.) und de Kuthy/Meurers (2001: 165ff., 201) für den Reanalyse-Ansatz zu zeigen versucht, dass dieser sich im Rahmen der HPSG gut modellieren lasse. Es herrscht also gewissermaßen eine „Pattsituation“ zwischen beiden Beschreibungsalternativen. $^{146}$

Für die Untersuchung der PP-Extraktion bei FVG ist es vermutlich unerheblich, ob das Phänomen als Reanalyse oder als Fall von Remnant-Movement gefasst wird. Im weiteren Verlauf dieser Untersuchung ist daher der Einfachheit halber von Reanalyse die Rede, wenn die syntaktische Seite des Phänomens angesprochen ist; da ein großer Teil der einschlägigen Forschungsliteratur ebenfalls von Reanalyse ausgeht (Fanselow 1987; Grewendorf 1989; de Kuthy 2001; de Kuthy/Meurers 2001; Winhart 2005; dagegen Fortmann 1996: 23-29; G. Müller 1998: 7-12; Schmellentin 2006: 100-106), knüpfen die weiteren Überlegungen damit zumindest an einen prominenten Strang der Forschung an.

Neben der Frage der syntaktischen Modellierung stellen die Restriktionen, denen PP-Extraktion unterworfen ist, ein weiteres zentrales Problemfeld der bisherigen Forschung dar; diese Restriktionen verdeutlichen die Gegenüberstellungen oben in (10) sowie hier in (19).

146 Gleichwohl ist festzuhalten, dass Remnant-Movement gegenüber Reanalyse auch in theoretischer Hinsicht wohl als das schwierigere Erklärungsmodell einzuschätzen ist, weil es, wie oben gezeigt, Scrambling voraussetzt. Scrambling stellt innerhalb des minimalistischen Programms (als der jüngsten Theorieversion der generativen Grammatik) ein umstrittenes und hochproblematisches Konzept dar. Eine Schwierigkeit der minimalistischen Modellierung liegt darin, dass Scrambling optional zu sein scheint. Da der Ausschluss von Optionalität eine Kernthese des Minimalismus ist, besteht Klärungsbedarf (vgl. Wilder/Gärtner 1997: 23). Problematisch ist auch, dass die Auffassungen von der Natur des Scrambling in teils scharfem Kontrast zueinander stehen. Es wird zum einen als Resultat syntaktischer Bewegungsoperation beschrieben (Webelhuth 1992: 161), zum anderen aber auch als Ergebnis einer freien Basisgenerierung (Fanselow 2001: 410, 433); Chomsky (1995: 325) selbst hatte im Anschluss an Vorstellungen aus der Frühzeit der generativen Grammatik sogar angenommen, dass Scrambling grundsätzlich außerhalb des Grammatiksystems anzusiedeln sei. Nicht zuletzt sind auch die motivierenden Faktoren umstritten. Wenn Scrambling als Bewegung beschrieben wird, kommt die Überprüfung grammatischer Merkmale (sog. „starker“ Merkmale), die im Minimalismus als wichtigster Grund für Bewegungsoperationen angesehen wird, jedenfalls nicht in Betracht (vgl. auch Wilder/Gärtner 1997: 23). 
(19) a. Über Syntax hat Bill ein Buch gelesen/geschrieben/ausgeliehen.

b. ?Über Syntax hat Bill ein Buch zerrissen/gestohlen.

Als wesentlicher Faktor, der die Abspaltbarkeit von NP und PP beeinflusst und der die Akzeptabilität bzw. Nichtakzeptabilität der Sätze in (10b) und (19b) erklären kann, werden in der Forschung lexikalisch-semantische Faktoren angesehen (Grewendorf 1989: 35, 47; Pafel 1993; 221; de Kuthy 2002: 93; Winhart 2005: 120ff.; Schmellentin 2006: 116-125). Den präzisesten Vorschlag zu einer Erfassung solcher Restriktionen hat de Kuthy (2001) vorgelegt. Sie geht zunächst von der Intuition aus, dass eine Aufspaltung besonders dann gut möglich ist, wenn Nomen und Verb eine besonders enge semantische Verbindung aufweisen. In Bezug auf Beispielpaare wie in (10) und (19) stellt sie fest: „,to write a book (the same holds for to read, to buy a book) is a more common, contextually unmarked action than to ,tear up a book““ (de Kuthy 2002: 97). Um die semantische Nähe zwischen Nomen und Verb genauer zu beschreiben, greift de Kuthy auf das von Pustejovsky (1995) entwickelte Modell des „Generativen Lexikons“ zurück, dessen Vorteil gerade in einer exakteren Beschreibung der semantischen Relationen von Lexikoneinträgen besteht (Pustejovsky 1995: 76). Die für die Verknüpfung mit anderen Einträgen relevanten Merkmale werden in einem speziellen Subset des Lexikoneintrags, der sog. „Qualia-Struktur“, beschrieben. Für das Nomen engl. book sähe die als Attribut-Wert-Matrix modellierte Qualia-Struktur wie folgt aus:

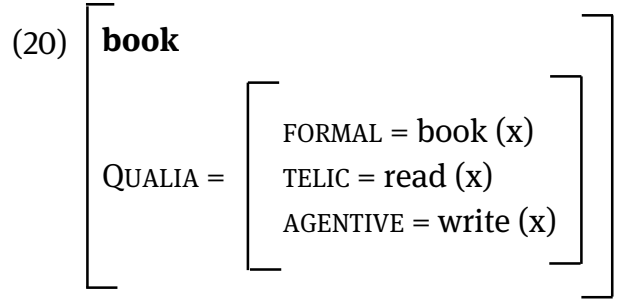

(vgl. Pustejovsky 1995: 101)

Die Qualia in (20) erfassen die unterscheidenden Merkmale des Denotats innerhalb einer spezifischen Domäne (FORMAL), seine Funktion (TELIC) ${ }^{147}$ sowie die Faktoren, welche es hervorgebracht haben (AGENTIVE). Relevant für de Kuthys Anwendung dieser Lexikon-Modellierung ist vor allem das TELIC-Attribut. Im Beispiel (21) enthält die TELIC-Position book das Ereigniskonzept read als Wert. Die enge semantische Beziehung zwischen dem Nomen book und dem Verb read kommt somit darin zum Ausdruck, dass die lexikalische Bedeutung des Verbs als

147 Mit der Aktionsartenmarkierung „telisch“ vs. „atelisch“ hat dieser Begriff nichts zu tun. 
Wert des nominalen TELIC-Attributes erscheint. Auf der Basis einer solchen Identitätsrelation formuliert de Kuthy dann eine lexikalisch-semantische Beschränkung für NP-PP-Spaltung: ,a nominal argument can be the source for argument raising only if one of the elements of its TELIC list is identical with the verb's NUCLEUS value [d. h. identisch mit der Bedeutung des Verbs, V. H.]“ (2002: 101).

PP-Extraktion kommt jedoch nicht nur im Fall von ein Buch über Syntax lesen vor, sondern ist auch mindestens mit den Verben kaufen, ausleihen oder schreiben möglich.

(21) a. Über Syntax hat er ein Buch ausgeliehen. (de Kuthy 2001: 34)

b. Über Chomsky hat er ein Buch gekauft.

c. Über Syntax hat er ein Buch geschrieben.

Um Fälle wie in (21) ebenfalls über semantische Nähe zu erklären, muss de Kuthy in einem wesentlichen Punkt über Pustejovskys Modellierung hinausgehen. Statt lediglich einen Wert für die Position TELIC anzusetzen - etwa read für die entsprechende Position von book -, plädiert sie dafür, dass das Attribut TELIC eine Liste von Verbbedeutungen als Wert enthalten soll. Der einschlägige Teil des Eintrags lautet somit wie in (22).

QUAL|TEL < borrow-rel, buy-rel, read-rel, write-rel> (de Kuthy 2002: 102)

Ob eine solche Liste die semantische Nähe zwischen Nomen und Verb und die daraus angeblich folgenden Restriktionen der PP-Extraktion angemessen erfasst, bleibt allerdings fraglich. Zum einen kommt diese Liste auf zirkuläre Weise zustande, indem genau die Verben in die TELIC-Liste aufgenommen werden, die die NP-PP-Spaltung zeigen - das zu Erklärende und die Erklärungsbasis fallen hier zusammen. Zum anderen stellt sich die Frage, ob Pustejovskys TELIC-Konzept mit der Auflistung einer ganzen Reihe von Verbereignissen nicht zu stark aufgeweicht wird: Dass ein Buch ausgeliehen oder geschrieben wird, kann nur noch schwer unter dem Begriff ,Zweck' gefasst werden.

Ein weiterer Einwand gegen de Kuthys Modellierung wäre schließlich, dass Qualia-Strukturen gerade für FVG kaum geeignet sind: FV wie haben oder bringen sind semantisch viel zu unspezifisch, als dass sie als ,Zweck' von Angst bzw. Aufführung aufgefasst werden könnten (Winhart 2005: 123). Das TELIC-Quale des Nomens scheint somit keine ausreichende Erklärung für die Restriktionen der PPExtraktion zu bieten. 
In eine ähnliche Richtung wie der Ansatz von de Kuthy geht auch der Vorschlag von Schmellentin (2006: 118), die annimmt, dass Extraktion dann lizensiert sei, wenn „die dem Verb inhärenten semantischen Merkmale mit den dem Nomen inhärenten übereinstimmen“. Eine solche Merkmalübereinstimmung sieht sie als gegeben an, wenn das Nomen über eine sog. „lcs“ („lexical conceptual structure“ im Sinne von Grimshaw 1990: 49ff.) verfüge. Damit sind fakultative Partizipanten eines Nomens gemeint (zur Abgrenzung von dessen obligatorischen, d. h. grammatischen Argumenten). Solche lexikalisch-semantischen Strukturen wiesen gerade die im Zusammenhang mit PP-Extraktion relevanten Werknomina wie Buch oder Bild auf (Schmellentin 2006: 118f.). Die Autorin beschreibt den Zusammenhang wie folgt: „Die Bezeichnung ,Übereinstimmung semantischer Merkmale، erfasst die [...] nötige Wechselbeziehung zwischen Nomen und Verb: Das Nomen braucht ein Verb mit bestimmten semantischen Eigenschaften, um seine lcs auszulösen, und das Verb braucht ein Nomen mit aktivierter lcs“ (ebd. 120). Welche Eigenschaften welcher Verben dies sind und wann genau sie die lexikalisch-semantische Struktur des Nomens ,auslösen', wird dabei allerdings offen gelassen. Zudem wäre zu zeigen, wie gerade FVG sich zu dieser These verhalten: FV gelten als semantisch leer oder zumindest relativ merkmalarm, und wie ein merkmalarmes oder gar merkmalloses Verb mit Merkmalen des Nomens abgeglichen werden kann, wäre im Einzelnen darzulegen (zu einem Lösungsansatz s. die Überlegungen in Kapitel 8.2).

\subsubsection{Ein lexikalisch-semantischer Ansatz}

\subsection{Domänenkompatibilität}

Die Schwierigkeiten der Ansätze von de Kuthy und Schmellentin bedeuten jedoch nicht, dass eine Analyse lexikalisch-semantischer Eigenschaften der beteiligten Phrasen grundsätzlich zum Scheitern verurteilt ist, wenn es um eine Erklärung der vorliegenden Beschränkungen geht. Im Weiteren ist zu zeigen, dass die Akzeptabilität der Spaltung in der Tat mit lexikalisch-semantischen Aspekten der NP bzw. der PP zusammenhängt, und zwar mit der Zugehörigkeit der jeweiligen Phrasen zu einer sog. konzeptuellen „Domäne“ („domain“, Langacker 1987: 183f.; Croft 1993/2003: 164-174; Croft/Cruse 2004: 15f.).

Als die „Domäne“ eines Konzepts wird in der kognitiven Linguistik das Hintergrundwissen bezeichnet, das für das Verständnis des betreffenden Konzepts unmittelbar relevant ist (hierzu und zum folgenden grundlegend Langacker 1987: 183f.). So ist das Konzept RADIUS erst vor dem Hintergrund des Konzepts KREIS interpretierbar, KREIS stellt deshalb die Domäne von RADIUS dar. Für den hier interessierenden Zusammenhang ist vor allem relevant, dass Konzepte jeweils vor 
dem Hintergrund unterschiedlicher Domänen interpretierbar sind. ${ }^{148}$ Das Konzept HuHn beispielsweise kann sowohl TIER als auch NAHRUNG als seine Domänen haben, das Konzept BucH ist sowohl vor dem Hintergrund der Domäne TEXT als auch vor der Domäne PHYSISCHES OBJEKT interpretierbar.

(23) a. Ein Huhn läuft über die Straße. = TIER

b. Wir bestellten Huhn mit Reis. = NAHRUNG

(24) a. ein rotes Buch $=$ PHYS. OBJEKT

b. ein interessantes Buch $=$ TEXT

Ein Beleg für die Relevanz von Domänen für lexikalische Strukturen ist nach Cruse (2000: 27) unter anderem darin zu sehen, dass sie jeweils eigene taxonomische Beziehungen unterhalten. ${ }^{149}$ Hyponyme zu Buch in der ОвјЕкт-Interpretation wären etwa Taschenbuch, Paperback, während Buch in der TeXT-Lesart mit Hyponymen wie Roman, Biographie in Relation steht. Als weitere Eigenschaft von Domänen ist festzuhalten, dass diese hierarchisch gestuft sein können (hierzu vor allem Croft 1993/2003: 169; Croft/Cruse 2004: 25f.). So ruft HuHN zunächst die Domäne TIER auf, TIER ist aber gleichzeitig in eine übergeordnete Domäne LEBEWESEN eingebettet. Die Domänenhierarchie zeichnet sich somit durch Transitivität der Relation aus.

Die Restriktionen bei PP-Extraktion lassen sich gut beschreiben, wenn man die Domänenzugehörigkeit der jeweiligen NPs bzw. PPs zu erfassen sucht. Bei unmittelbar akzeptablen Beispielsätzen stimmen NP und PP hinsichtlich der Domäne, der sie angehören, überein. Das Nomen in der extrahierten PP kann hier auf das der NP bezogen werden, ohne dass ein Domänenwechsel angenommen werden muss.

(25) a. Über Syntax hat er ein Buch geschrieben.

b. Buch $=$ TEXT, über Syntax $=$ INHALT VON TEXT

(26) a. Über Syntax hat er ein Buch gelesen.

b. Buch $=$ TEXT, über Syntax $=$ INHALT vON TEXT

148 Was die kognitive Linguistik als unterschiedliche Domänenzugehörigkeit eines Konzepts auffasst, findet sich auch in anderen theoretischen Ansätzen in ähnlicher Weise wieder, vgl. u. a. Apresjan (1973) (,regular polysemy“); Bierwisch (1983) (,konzeptuelle Verschiebung“); Lutzeier (1995: 49f.) („Aspekte“).

149 Dem Begriff „Domäne“ („domain“) entspricht bei Cruse (2000: 27) der Terminus „Facette“ (,facet“). 
Die nicht-akzeptablen Sätze in (27) und (28) zeigen demgegenüber insofern einen Domänenkonflikt zwischen NP und PP, als Über Syntax nur auf die Domäne TEXT, nicht aber auf die Domäne Овјект bezogen werden kann.

(27) a. *Über Syntax hat er ein Buch zerrissen.

b. Buch $=$ PHYS. OBJEKT, über Syntax $=$ INHALT VON TEXT

a. *Über Syntax hat er ein Buch fallen gelassen.

b. Buch $=$ PHYS. OBJEKT, über Syntax $=$ INHALT VON TEXT

Daraus lässt sich im Hinblick auf die Beschränkungen der PP-Extraktion die Hypothese ableiten, dass die Extraktion einer PP aus einer NP nur dann akzeptabel ist, wenn die in der NP und der PP ausgedrückten nominalen Konzepte derselben Domäne angehören.

Welcher Domäne das NP-Konzept zuzurechnen ist, ob also Buch in der TEXToder der ОвJEKT-Lesart vorliegt, wird, wie bereits angedeutet, im Wesentlichen durch den konzeptuellen Gehalt des jeweiligen Verbs bestimmt. Die Verben zerreißen und fallen lassen referieren - zumindest in ihrer grundlegenden, häufigsten Lesart - auf die Manipulation physischer Gegenstände, sie präferieren somit ein Konkretum als Patiens. Deshalb sind hier nur solche Adjunkte ohne weitere Kontextannahmen plausibel, die sich auf eine Handlung am konkreten Gegenstand beziehen:

(29) a. Er hat ein Buch zu Asche verbrannt.

b. Er hat ein Buch in seine Einzelteile zerrissen.

c. Er hat ein Buch auf den Boden fallen lassen.

Mit einem Adjunkt, das eine mentale Aktivität bezeichnet, sind diese Verben nur schwer kombinierbar, vgl. (30). Hier müssen schon entlegene Kontexte herangezogen werden, damit die Äußerung als sinnvoll bewertet werden kann.

(30) a. 'Mit großem Erkenntnisgewinn hat er ein Buch verbrannt.

b. 'Mit großer innerer Anteilnahme hat er ein Buch fallen lassen.

Ein Verb wie schreiben oder lesen dagegen referiert primär auf die Produktion bzw. Rezeption von TEXT, bezeichnet also in erster Linie einen geistigen Akt, auch wenn dieser untrennbar mit der Herstellung bzw. Abarbeitung eines konkreten Textträgers verbunden ist. Ein Satz wie (31a) ist daher natürlicher als ein Satz wie (31b), der sehr stark auf besondere Kontexte angewiesen ist. 
(31) a. Der Autor hat in den letzten Monaten ein interessantes Buch geschrieben.

b. 'Der Autor hat in den letzten Monaten ein Buch mit einem roten Einband geschrieben.

(32) a. Ich habe gestern ein spannendes Buch gelesen.

b. Ich habe gestern ein Buch mit einem roten Einband gelesen.

Neben den Verben schreiben und lesen, die eine klare Domänenzuweisung für die Objekt-NP mit sich bringen, gibt es auch solche, die hinsichtlich ihrer Domänen unterspezifiziert sind, z. B. kaufen oder ausleihen:

a. Er hat ein rotes Buch gekauft/ausgeliehen. = OBJEKT

b. Er hat ein interessantes Buch gekauft/ausgeliehen. = TEXT

Ein Buch kaufen und ein Buch ausleihen kann sich also nach Ausweis der Beispiele in (33) prinzipiell sowohl auf den Erwerb eines Textes als Information als auch auf den Erwerb eines Gegenstandes beziehen. Da das Verb dem Nomen also keine Domäne zuweist und Buch hier ebenso als TEXT wie als OBJEKT bestimmde bar ist, steht einer Extraktion der PP nichts im Wege, wie das Beispiel (34) mit nicht-attribuiertem Nomen zeigt.

(34) a. Über Syntax hat er ein Buch gekauft.

b. Über Syntax = INHALT von TEXT, Buch = TEXT/OBJEKT

Sobald Buch jedoch in Richtung auf die OBJEKT-Lesart disambiguiert wird, ist die Extraktion schwieriger. So wirkt die Verschiebung der PP in der Äußerung (35a), die Buch durch das Attribut rot klar als OBJEKT ausweist, unnatürlich. Hier muss relativ viel an Kontext bereitgestellt werden, damit der Satz plausibel erscheint.

(35) a. 'Über Syntax hat er sich ein rotes Buch ausgeliehen.

b. Über Syntax = INHALT VON TEXT, rotes Buch $=$ PHYS. OBJEKT

Wird Buch durch das Adjektiv interessant hingegen auf die TEXT-Lesart hin festgelegt, funktioniert die Extraktion besser:

(36) a. Über Syntax hat er sich ein interessantes Buch ausgeliehen.

b. Über Syntax = INHALT VON TEXT, interessantes Buch $=$ TEXT 
Insgesamt kann also festgehalten werden, dass Extraktion zulässig ist, wenn die betreffenden Domänen übereinstimmen wie in (25) und (26) oder die Domänen jeweils unterspezifiziert sind wie in (34). Somit ist die folgende grundlegende Beschränkung für PP-Extraktion formulierbar:

\section{i. Domänenkompatibilität}

Die Extraktion einer PP aus einer NP ist akzeptabel, wenn für die durch die NP und PP ausgedrückten Konzepte eine gemeinsame Domäne konstruiert werden kann.

Diese Bedingung für Extraktion stimmt übrigens mit dem von Croft (1993/2003) formulierten Grundsatz der „conceptual unity of domain“ überein, dem zufolge alle syntaktischen Einheiten eines Satzes, d. h. vorzugsweise die Satzglieder, einer einzigen konzeptuellen Domäne zugeschlagen werden:

conceptual unity of domain

„[A]ll of the elements in a syntactic unit must be interpreted in a single domain.“

(Croft 1993/2003: 162; vgl. Croft/Cruse 2004: 70) 150 $^{150}$

Dieser Regel liegen, wie Croft (1993/2003: 202) andeutet, letztlich pragmatische Faktoren zugrunde: Der Sprecher gestaltet seinen Redebeitrag möglichst semantisch kohärent und sucht damit der Grice'schen Maxime der Relation zu genügen.

Erwähnenswert ist in diesem Zusammenhang, dass auch in dem folgenden Beispiel (37) eine Extraktion möglich ist, obwohl dickes Buch eher der ОвJEKт-Domäne anzugehören scheint und daher auf den ersten Blick ein Verstoß gegen die Beschränkung (i) vorläge.

Über Syntax hat er sich ein dickes Buch gekauft.

150 Croft begreift diese Interpretationsregel als ein Gestaltgesetz, wie aus dem vollständigen Zitat der Stelle hervorgeht; damit ist ein wesentlicher Unterschied zu der herkömmlichen kompositionalen Satzsemantik markiert: „Unlike the typical problems of semantic composition discussed in the formal semantic literature, where the meaning of the whole is at least in part determined by the meanings of the parts, the meaning of the parts here seems to be determined in part by the meaning of the whole. I will argue here that the 'meaning of the whole' that affects the meanings of the parts is what I call the conceptual unity of domain: all of the elements in a syntactic unit must be interpreted in a single domain" (Croft 1993/2003: 162). 
Dickes Buch ist allerdings bei näherer Betrachtung durchaus ambig. Dickes Buch UMFANGREICHES OBJEKT steht in einer sehr engen metonymischen Beziehung zu LANGER TEXT (relevant ist hier offensichtlich das metonymische Übertragungsmuster BEHÄLTER-INHALT). Aus diesem Grund ist dick auch in Kombination mit Adjektiven verwendbar, die eindeutig auf die TEXT-Domäne verweisen; entsprechend ist in diesem Fall die Extraktion einer PP möglich, wie (38) zeigt.

(38) a. Er hat sich ein ziemlich dickes, aber unglaublich spannendes Buch gekauft.

b. Über Syntax hat er sich ein ziemlich dickes, aber unglaublich spannendes Buch gekauft.

\subsection{Interpretierbarkeit der PP}

Wenn die Akzeptabilität der Extraktion in (38b) zum Teil nicht leicht zu beurteilen ist, so ist doch für Sätze wie die in (39) unstrittig, dass es sich um ungrammatische bzw. nur unter besonderen Kontextbedingungen mögliche Äußerungen handelt.

(39) a. ${ }^{\star}$ Mit roten Haaren hat er eine Freundin. (Beispiel de Kuthy 2002: 24)

b. *Aus Blech habe ich eine Tasse zertrümmert.

c. 'Mit Tee hat sie eine Tasse fallen lassen.

d. *Mit Blattläusen habe ich heute eine Rose gepflückt.

e. *Über die Leine hatte der Ingenieur eine Brücke zerstört.

(vgl. aber: Über die Leine hatte der Ingenieur eine Brücke gebaut, die ewig hielt.)

Da die Domänen der jeweiligen PPs und NPs kompatibel sind und die Beispiele in (39) daher durchaus der Beschränkung (i) genügen, ist zu fragen, welche Faktoren die Domänenkompatibilität als lizensierenden Faktor hier nicht zum Tragen kommen lassen.

Um hier eine Lösung zu finden, ist ein Blick auf PPs hilfreich, die ohne Probleme in die Spitzenposition eines Satzes gerückt werden können. Zunächst seien hierzu die mit-PPs betrachtet, vgl. (40).

(40) a. Mit ihrer Tochter ging sie bummeln.

b. Mit dem Hammer zertrümmerte er den Stein.

c. Mit großen Schritten betrat sie den Saal.

d. Mit einem freundlichen Gruß verabschiedete er sich. 
Den adverbialen PPs in (40) kann in jedem Fall eine semantische Interpretation zugewiesen werden: In (40a) ist die PP KOMITATIV, in (40b) INSTRUMENTAL und in (40c) und (40d) MODAL. Hinzu kommt noch die Möglichkeit einer Patiens- bzw. Thema-Lesart, wie sie bei einem Präpositionalobjekt vorliegt, vgl. (41).

(41) Über Syntax hat er sich ein dickes Buch gekauft.

Für eine adverbale mit-PP in Topikposition steht somit offenbar eine bestimmte Menge an Interpretationsmöglichkeiten zur Verfügung. Die Beispiele in (39) sind nun deshalb ungrammatisch, weil keine Interpretation aus dieser Menge in Betracht kommt: Mit roten Haaren kann nicht als komitatives, instrumentales oder modales Argument auf den Zustand eine Freundin haben bezogen werden, auch mit Blattläusen und eine Rose pflücken können in keine sinnvolle Beziehung zueinander gesetzt werden (es sei denn man beabsichtigte mit der Lesart ,zusammen mit Blattläusen' eine komische Wirkung).

Auch die aus-PP in (39b) ist nicht auf das Prädikat eine Tasse zertrümmern beziehbar, da keine Interpretationsmöglichkeit bereitsteht, die eine PP in Topikposition plausibel erscheinen lässt. Die Handlung zertrümmern ist weder durch die Angabe eines Ausgangspunkts (aus dem Schrank) noch durch eine Materialeigenschaft (aus $X$ gemacht) qualifizierbar - das Rollengerüst von zertrümmern sieht eine solche Rolle gar nicht vor.

Besonders deutlich zeigt sich die fehlende Interpretationsmöglichkeit der topikalisierten PP im Fall von (39e). Die PP über die Leine ist wegen des Akkusativs als direktionale Ortsangabe zu interpretieren. Das Verb zerstören indes ist mit einer direktionalen Angabe nicht kompatibel (*etwas über etwas zerstören).

Auf der Basis dieser Beobachtungen lässt sich neben der Bedingung der Domänenkompatibilität eine zweite Bedingung für PP-Extraktion formulieren:

\section{ii. Interpretierbarkeit der PP}

Die Extraktion einer PP aus einer NP ist akzeptabel, wenn die topikalisierte PP semantisch interpretierbar ist, d. h. als Satzglied auf V oder VP bezogen werden kann.

Die PP muss also, anders formuliert, syntaktisch entweder als Komplement zu V (Grewendorf 1989: 47) wie im Fall des Präpositionalobjekts in (41) oder als VPAdjunkt wie in (40) analysierbar sein.

An dieser Stelle ist allerdings noch einmal die Gegenprobe $\mathrm{zu}$ machen. Es ist $\mathrm{zu}$ fragen, ob auch die als grammatisch bewerteten Beispiele in (40) der Interpretierbarkeitsbedingung genügen. Die oben behandelten über-PPs zeichnen sich in 
der Tat dadurch aus, dass ein topikalisiertes über $X$ auch in anderen Äußerungen entsprechend interpretiert werden kann. Für über $\mathrm{X}$ besteht (neben lokalen Interpretationen wie in über die Brücke gehen u. ä.) generell auch die Lesart „ZUM KoMMUNIKATIONSGEGENSTAND X“. ${ }^{151}$

(42) a. Der Redner sprach/scherzte über Syntax.

b. Die Gelehrten stritten über die Syntax des Deutschen.

Wie (42) zeigt, kommen über-PPs in der Bedeutung ,ZUM KommuniKATIONSGEGENSTAND X“ also nicht nur als Attribute zu einer NP (ein Buch über Syntax), sondern auch als V-Komplemente vor. Eine aus einer NP in die Topikposition gerückte über-PP erweist sich damit als semantisch interpretierbar. Dementsprechend kann auch einer extrahierten über-PP die Lesart „ZUM KoMmUNIKATIONSGEGENSTAND $\mathrm{X}$ “ zugewiesen werden. ${ }^{152}$

Die Geltung der Bedingung (ii) wird auch durch die Ungrammatikalität der folgenden Extraktion in (43) belegt.

(43) a. Ihr haben auch früher schon viele Bücher über dieses Thema Eindruck gemacht.

b. *Über dieses Thema haben ihr auch früher schon viele Bücher Eindruck gemacht.

(Schmellentin 2006: 102)

Die PP über dieses Thema bezeichnet hier den Gegenstand einer schriftlichen Äußerung Buch; die Bedeutung der PP ist daher „ZUM TeXTinHALt X“, vielleicht auch allgemeiner „ZUM KOMMUNIKATIONSGEGENSTAND X“. (43b) ist ungrammatisch oder doch zumindest problematisch, weil diese Interpretation nur für die von der NP dominierte PP gilt. Als Satzglied, das sich auf jmdm. Eindruck machen bezieht, ist die PP über dieses Thema indes nicht geeignet: Der Lexikoneintrag jmdm. Eindruck machen hält keine Position bereit, welche die PP ausfüllen könnte. Allenfalls wäre eine vage limitative Angabe ,im Hinblick auf X/was X betrifft“ denkbar; solche limitativen Angaben werden aber im Regelfall nicht durch über-

151 Damit ist nicht die Rolle „THEMA“ gemeint. Es handelt sich bei der Angabe „zum Thema/Inhalt“ lediglich um eine ad-hoc-Beschreibung der PP-Bedeutung. Eine weitergehende rollensemantische Einordnung ist schwierig.

152 Vgl. auch die Rolle „TOPIC“ im Framenet-Modell (https://framenet.icsi.berkeley.edu/fndrupal/frameindex; Zugriff 06.04.2021). 
Phrasen ausgedrückt, weshalb diese Lesart hier nicht zur Verfügung steht und der Satz als nicht-akzeptabel einzustufen ist.

Erwähnenswert sind in diesem Zusammenhang auch Fälle, in denen der PP in Topikposition eine andere Interpretation zugewiesen wird, als ihr in der NPdominierten Position zukommt. Dies betrifft etwa (44).

(44) Von seiner Ex-Freundin hat Rudi alle Briefe zerrissen.

(Schmellentin 2006: 23)

In der Ausgangsposition ist die PP von seiner Ex-Freundin als SouRCE oder AUCTOR (Schmellentin 2006: 121) zu bestimmen. Das Rollengerüst von zerreißen sieht keine Angabe der QuELLE vor, (44) müsste daher ungrammatisch sein. Dass der Satz trotzdem unproblematisch ist, kann darauf zurückgeführt werden, dass die topikalisierte PP reinterpretiert werden kann, und zwar als limitative Angabe. (44) ist daher durch (45) paraphrasierbar.

(45) Was seine Ex-Freundin betrifft, hat Rudi alle Briefe zerrissen.

Von-Phrasen in limitativer Funktion sind durchaus verbreitet, wie (46) zeigt, deshalb ist auch für (44) eine solche Interpretation zugänglich:

(46) a. Von Musik hat er keine Ahnung.

b. Was Musik angeht, hat er keine Ahnung.

Topikalisierte PPs, die nicht über entsprechende Interpretationsmöglichkeiten verfügen, sind dementsprechend schlechter zu bewerten:

(47) a. 'An seine Ex-Freundin hat Rudi alle Briefe zerrissen.

b. ??Nach China hat Rudi alle Briefe zerrissen.

\subsection{Schwacher Satzgliedstatus der NP}

Wie zu Beginn dieses Kapitels dargelegt, hatte Grewendorf (1989: 45, 47) postuliert, dass die Interpretation einer extrahierten PP als Satzglied nur dann möglich sei, wenn die NP zuvor als Teil eines komplexen Verbalausdrucks NP+V reanalysiert worden sei. Dieser Vorschlag ist deshalb überzeugend, weil hieraus eine weitere klare Bedingung abgeleitet werden kann, unter der die PP als Satzglied interpretierbar ist: Je mehr NP und V eine Einheit bilden und je schwächer damit der Satzgliedstatus, die syntaktische Autonomie der dominierenden NP ist, desto 
leichter kann die PP als Satzglied auf den Verbalausdruck bezogen werden. Eine weitergehende Begründung für diesen Zusammenhang gibt Grewendorf nicht; es steht aber zu vermuten, dass das Theta-Kriterium hier eine Rolle spielt. Dies lässt sich gut an Grewendorfs Beispielsatz (48) demonstrieren.

Über Becker hat Hans einen Sieg errungen.

(Grewendorf 1989: 46)

Sieg käme im Regelfall die Rolle des Patiens von erringen zu. Die NP einen Sieg bildet jedoch zusammen mit erringen ein komplexes Prädikat - genauer gesagt sogar ein FVG im Sinne dieser Untersuchung. Im Rahmen eines FVG weist erringen seinem Argument keine Rolle zu. Die Patiensrolle ist also gewissermaßen frei und kann dementsprechend von der PP über Becker eingenommen werden. Daher ist für (48) auch die Paraphrase Hans hat Becker besiegt möglich, in der sich Becker eindeutig als Patiens erweist.

Der komplexe Verbalausdruck kommt Grewendorf zufolge durch eine Inkorporation der NP zustande. Dabei wird allerdings offen gelassen, was genau unter Inkorporation zu verstehen ist. Da für das Deutsche in der Regel nur habituelle $\mathrm{NP}+\mathrm{V}$-Kombinationen des Typs Flöte spielen als Fälle von Inkorporation beschrieben werden (s. Abschnitt 7), sei hier im weiteren in Anlehnung an Talmy (1985) stattdessen der etwas allgemeinere Begriff der „Verschmelzung“ („conflation“) gewählt, um die hier vorliegende Beziehung zwischen NP und V zu erfassen (zu „conflation“ in diesem Sinne vgl. auch Murphy 2010: 176). ${ }^{153}$ Im Fall einer solchen Verschmelzung wird eine Rolle nicht, wie üblich, als NP kodiert, sondern als Bestandteil der semantischen Struktur des Verbs (insofern wäre Grewendorfs Terminus durchaus treffend, da das Verb die Rolle quasi inkorporiert). So ist die lexikalische Bedeutung des Verbs entgleisen als Kombination eines abstrakten Bewegungsereignisses mit einer Rolle SoURCE, nämlich Gleis, zu beschreiben. ${ }^{154}$ Ähnliche Verschmelzungen zeigen etwa auch die Verben bedachen oder töpfern. Die Aufgabe der Rollenkodierung, die normalerweise in den Bereich der Syntax fällt, wird hier somit innerhalb des Lexikons gelöst.

Neben vollständigen und morphologisch durchsichtigen Verschmelzungen dieser Art bestehen auch partielle Verschmelzungen. Diese sind dann gegeben,

153 In der Tradition des Minimalismus ist der Begriff „conflation“ anders besetzt, vgl. dazu z. B. Hale/Keyser (2002: 63 ) sowie die entsprechenden Ausführungen in Kapitel 8.1.2.

154 Die semantische Struktur von entgleisen ließe sich im Stile von Jackendoff (1990) wie folgt angeben (vgl. Murphy 2010: $184 \mathrm{zu}$ engl. derail): entgleisen: [EVENT GO ([THING], [PATH FROM (PLACE ON ([тнing Gleis])])])]. 
wenn das Verb zwar nicht die gesamte normalerweise nominal ausgedrückte Rolle enthält wie bei entgleisen, aber immerhin wesentliche Teilaspekte der Rolle bereits spezifiziert und damit die in seinem Argument enthaltene Information teilweise vorwegnimmt. Dies ist etwa bei den Verben schreiben und lesen der Fall. Schreiben ist als Herstellungsverb zu charakterisieren (zu dieser Verbklasse vgl. auch Ehrich/Rapp 2000: 284). Von Herstellungsverben wie schaffen oder produzieren unterscheidet sich seine lexikalische Struktur allerdings signifikant: Schreiben ist als ,Geschriebenes herstellen' o. ä. zu paraphrasieren, es enthält also bereits insofern semantische Information über seine Objekt-NP, als diese auf eine bestimmte Klasse von möglichen Referenten beschränkt ist. Die Objekt-NP Buch ist daher in Bezug auf schreiben als verhältnismäßig „schwach“ anzusehen, da ein Teil der Information über die Rolle bereits in der lexikalischen Struktur des Verbs enthalten ist und die NP lediglich Zusatzinformationen angibt, indem sie die Art des Geschriebenen (in diesem Fall ,Buch' statt ,Aufsatz' oder ,Roman') näher eingrenzt. Auch lesen präsupponiert, dass die Objekt-NP ein Konzept der Klasse ,Geschriebenes' kodiert. Dadurch unterscheiden sich Phrasen wie ein Buch lesen bzw. ein Buch schreiben auch von z. B. von ein Buch genießen, studieren, mögen oder zerreißen, deren Verben keine vergleichbaren Spezifikationen enthalten. ${ }^{155}$

Ein Indiz für das Vorliegen einer solchen partiellen Verschmelzung der NP mit dem Verb bzw. die damit korrespondierende „Schwäche“ der Objekt-NP ist die Möglichkeit einer Paraphrase durch etwas + PP, vgl. (49a) gegenüber (49b).

(49) a. Etwas über Syntax schreiben/lesen/publizieren.

b. 'Etwas über Syntax genießen/studieren.

155 In der traditionellen Lexikologie werden Relationen wie die zwischen lesen/schreiben und Buch auch als sog. „,wesenhafte Bedeutungsbeziehungen“ behandelt (Porzig 1973: 78; vgl. Lutzeier 1995: 89f.). Porzig versteht hierunter solche „bedeutungsbeziehungen zwischen wörtern, dass mit dem einen das andere implicite mitgesetzt ist“ (1973: 78) und bezieht diese Beschreibung u. a. auf Wortpaare wie greifen und Hand, sehen und Auge, gehen und Füße. - Grundlegende Überlegungen zur semantischen Nähe bzw. Distanz zwischen Verben und bestimmten Typen von Objekten finden sich auch bei Lazard (2001: 882-884): Die Nähe zwischen Verb und Objekt ist bei sog. „objets coalescents“ am größten, bei den in der Skala rechts folgenden Objekttypen („non-marqué“, „marqué“, „oblique“) jeweils geringer. 
Dieser Test weist allerdings auch die direkten Objekte zu Verben wie schenken als schwach aus, vgl. (50b). Damit ist korrekt vorhergesagt, dass auch die Extraktion in (51) akzeptabel ist.

(50) a. Anna hat ihrer Mutter ein Buch über Syntax geschenkt.

b. Anna hat ihrer Mutter etwas über Syntax geschenkt.

Über die Toskana hat Anna ihrer Mutter schon viele Bücher geschenkt.

(Schmellentin 2006: 118)

Dass die NP ein Buch in (50a) als schwach im zuletzt beschriebenen Sinne zu gelten hat, ist hier allerdings - im Unterschied zu den Fällen lesen und schreiben weniger auf die interne Semantik des Verbs als vielmehr auf den Satzkontext zurückzuführen. Durch die PP über Syntax ist das Verb schenken hier bereits auf eine sehr enge Klasse von Objekten festgelegt, deren Prototyp Buch ist (man kann schlecht ein Bild oder eine Vase über Syntax schenken). Da die PP folglich bereits die genaue lexikalische Spezifikation der Objekt-NP vorwegnimmt - es kann sich in diesem Fall nur um ein Buch handeln -, ist die Objekt-NP schwach. Sie kann deshalb durch etwas ersetzt werden und lässt im Rollengerüst von schenken einen Platz für eine andere THEMA-Rolle frei, hier die PP über Syntax. Diese ist als Satzglied interpretierbar, das auf (Buch) schenken zu beziehen ist, und kann daher auch topikalisiert werden. ${ }^{156}$

Grewendorfs Beobachtung, dass NP und Verb zu einem komplexen Prädikat verschmolzen sein müssen, damit PP-Extraktion möglich ist, kann hier somit als drittes Kriterium reformuliert werden:

\section{iii. Schwäche der Objekt-NP}

Extraktion der PP aus einer NP ist umso leichter, je „schwächer“ die NP ist, d. h. je weniger Rollen-Information sie enthält und je mehr sie dementsprechend mit dem Verb zu einem komplexen Prädikat verschmilzt.

156 Schmellentin (2006: 118) konstruiert indes eine direkte semantische Nähe zwischen geben und Buch, da Bücher (etwa zusammen mit Weinflaschen) zu den typischen Geschenken gehörten. Gleichwohl kann nicht behauptet werden, dass geben und Buch eine semantische Nähe zueinander aufwiesen, die dem Verhältnis von schreiben/lesen und Buch entspräche. In den zuletzt genannten Fällen ist die Nähe in der Tat in der inhärenten Bedeutung von Verb und Nomen begründet. 
In diesem Zusammenhang ist freilich darauf aufmerksam zu machen, dass nicht nur der Satzkontext, sondern auch der erweiterte Kontext zur Bildung eines komplexen Verbalausdrucks führen kann. Auf die Bedeutung einer angemessenen Kontexteinbettung für Extraktion hatten bereits Fanselow (1991: 184f.) und de Kuthy (2001: 47) hingewiesen, vgl. dazu nochmals das eingangs zitierte Beispiel (14).

(14)’ a. *Über Semantik hat er ein Buch geklaut.

b. Gestern wurde in der Bibliothek eine Anzahl von Linguistikbüchern geklaut. Vor allem Syntaxbücher verschwanden dabei. Über Semantik wurde jedoch nur ein einziges Buch geklaut.

(de Kuthy 2002: 3; vgl. de Kuthy/Meurers 2001: 197)

In (14b)' wird der Komplex Buch klauen durch den ersten Satz als Information eingeführt. In den folgenden beiden Sätzen bilden NP und V gemeinsam den Hintergrund, auf den sich im letzten Satz dann auch die in Fokusposition befindliche PP bezieht, welche die neue Information enthält (vgl. auch de Kuthy 2001: 53f.). Die Verschmelzung von NP und V zu einem komplexen Verbalausdruck und die entsprechend leichtere semantische Interpretierbarkeit der PP als topikalisierbares Satzglied geht somit allein nicht auf lexikalische Faktoren zurück, sondern kann offenbar auch durch informationsstrukturelle Gegebenheiten bedingt sein.

Mit den hier postulierten Bedingungen für PP-Extraktion - Kompatibilität der Domänen von NP und PP, Interpretierbarkeit der PP, Schwäche der NP konnte keine abgeschlossene Theorie des Phänomens vorgelegt werden; hierzu bedürfte es wesentlich weiter gehender Untersuchungen. Es wurden lediglich Grundzüge herausgearbeitet, die für die Einordnung von Extraktion bei FVG hilfreich sind und die in einer allgemeinen Theorie der PP-Extraktion zu berücksichtigen wären.

\subsubsection{Extraktion bei FVG}

Bei einem FVG liegt nun, wie bereits Grewendorfs Beispiel (48) deutlich gemacht hat, eine NP vor, die in sehr ausgeprägter Weise „schwach“ im eben beschriebenen Sinne ist: Die NP Sieg in dem Beispiel einen Sieg erringen enthält überhaupt keine Rolleninformation, da diese im Zuge der Argumentvererbung an das Verb vollständig weitergegeben ist (s. o. Abschnitt 6.1). FVG entsprechen daher voll und ganz dem Kriterium iii, und dementsprechend leicht fällt die Extraktion einer PP aus einem FVG, wie die Beispiele in (12) gezeigt haben. 
Kriterium ii - die Interpretierbarkeit der PP als Satzglied - ist bei FVG ebenfalls erfüllt. Dies lässt sich daran zeigen, dass FVG meist durch ein einfaches Verb paraphrasierbar sind, sei dieses etymologisch verwandt oder nicht. Dadurch, dass Angst haben vor NP neben sich fürchten vor NP steht und im letzten Fall die vor-Phrase den Stimulus bezeichnet, ist klar, dass auch für das FVG Angst haben vor NP nur die Stimulus-Rolle in Frage kommt.

Auch im Hinblick auf das Kriterium i - die Kompatibilität der Domänen von NP und PP - genügen FVG der betreffenden Beschränkung: Die NPs von FVG stellen generell Ereignisnomina dar (s. o. Kapitel 3.2.2 und 3.4); für PPs, die von diesen dominiert sind, ist daher nichts anderes zu erwarten, als dass sie Mitspieler oder Umstände genau dieses Ereignisses kodieren. Die auf ein Ereignisnomen beziehbaren PPs gehören somit genau derselben „Szene“ an, welche durch dasselbe Nomen eröffnet wird. Prüft man die Extraktionsbeispiele in (52)-(55), so zeigt sich dies in aller Deutlichkeit:

(52) a. Vor Hunden hat der Junge Angst.

b. [Vor Hunden] ist Stimulus zu Angst

(53) a. Zur Syntax stellte sie eine Frage.

b. [Zur Syntax] ist KommuniKationsGEgENSTAND von Frage

(54) a. Zur Währungsunion machte sie eine Bemerkung.

b. [Zur Währungsunion] ist KommuniKATIONSGEGENSTAND zu Bemerkung

a. [Zur Währungsunion] ist KommuniKationsGEGENSTAND zu Bemerkung

b. [In Schweden] ist ORT von Urlaub

Dass eine von einem Ereignisnomen dominierte PP einer anderen Domäne angehört, ist vor diesem Hintergrund nahezu undenkbar: Die Mitspieler eines Ereignisses können kaum einer anderen Domäne angehören als derjenigen des Ereignisses selbst - andernfalls wären sie kaum als „Mitspieler“ identifizierbar. ${ }^{157}$

157 Die prinzipielle Kompatibilität der Domänen des Verbs und seiner Aktanten ist übrigens auch der Grund dafür, dass die Mitspieler eines Verbalereignisses auch häufig mit Hilfe von Bildungen versprachlicht werden können, die von dem betreffenden Verb abgeleitet sind: kaufen $<$ KÄUFER, GEKAUFTES>, lesen <LESER, GELESENES>, fragen <FRAGENDER, GEFRAGTES> usw.; vgl. als beliebig herausgegriffenen Beispiele „<hander, handee, handed “ bei Goldberg (1995: 51) sowie „<kisser, kissed ““ (Ackerman/Webelhuth 1998: 200). Ohne Domänenkompatibilität wäre dies nicht möglich. 
Angesichts der Leichtigkeit von PP-Extraktion bei FVG stellt sich allerdings umso nachdrücklicher die Frage, weshalb bei einigen FVG Extraktion problematisch zu sein scheint, wie die folgenden - bereits in (13) angeführten - Beispiele zeigen:

(56) a. Er machte einen Sprung in die Luft.

b. 'In die Luft machte er einen Sprung.

(57) a. Er machte eine Bewegung in die falsche Richtung.

b. 'In die falsche Richtung machte er eine Bewegung.

(58) a. Ich habe Hoffnung auf eine Verbesserung meiner Finanzlage.

b. ?Auf eine Verbesserung meiner Finanzlage habe ich Hoffnung.

Aufschlussreich ist hier, dass die Akzeptabilität der hier genannten Extraktionen sich entscheidend verbessert, wenn das FVG durch ein adnominales Attribut erweitert wird wie in (59)-(60) oder negiert bzw. quantifiziert ist wie in (61).

(59) Über den Wassergraben hat das Pferd seinen besten Sprung gemacht.

(60) Den Punkt sicherte dann Ivanschitz mit seinem verwandelten Foulelfmeter. [...] Beim Anlauf entscheidet sich der 28-Jährige dann grundsätzlich für eine Ecke. „Dann habe ich gesehen, dass der Torhüter in diese Richtung schon eine Bewegung gemacht hat“, so der österreichische Nationalspieler. „Also musste ich hoch schießen. Ich bin froh, dass der gepasst hat. (Rhein-Zeitung, 27.08.2012, S. 20; Zugriff 06.04.2021)

(61) Auf eine schnelle Verbesserung der Lage habe ich wenig/keine Hoffnung.

Die Akzeptabilität der Extraktion geht somit mit einem erhöhten Informationsgehalt des FVG einher. Das ist ein Indiz dafür, dass pragmatische Faktoren hier eine entscheidende Rolle spielen. Dies erscheint insofern grundsätzlich naheliegend, als PP-Extraktion mit einem informationsstrukturellen Effekt, nämlich mit der Kodierung von Kontrasten, verbunden ist, vgl. dazu zunächst die Beispiele in (62).

(62) a. Über CHomsky hat er ein Buch gelesen, nicht über Searle.

b. Über Chomsky hat er ein BucH gelesen, über Searle bloß einen AUFsatz. 
In (62a) liegt ein Kontrast hinsichtlich der fokussierten Information vor, in (62b) werden zwei mögliche Hintergründe einander gegenübergestellt. Die Akzeptabilität der Extraktion hängt also davon ab, ob ein Kontrast zu einem anderen Informationselement vorausgesetzt werden kann. Vor diesem Hintergrund sind die nicht voll akzeptablen Beispiele in (56)-(58) noch einmal in den Blick zu nehmen. So ist in dem problematischen Fall (58b) eine Kontrastierung der NP Hoffnung mit anderen NPs nicht möglich, vgl. (63).

(63) 'Auf eine Verbesserung meiner Lage habe ich HoFfnung [und nicht eine andere mentale Disposition X].

Hier ist die Menge der NPs, die einen Kontrast zu Hoffnung bilden könnten, zu klein. Es gibt zu wenig parallel gebildete FVG, die hier einsetzbar wären. Allenfalls Vertrauen haben käme hier in Frage.

(64) Auf eine Verbesserung meiner Lage habe ich nicht HoFfnung, sondern VerTRAUen.

Die wenigen NPs, die hier abgesehen von Vertrauen als Kandidaten zur Auswahl stehen, weisen durchweg einen anderen präpositionalen Anschluss auf, was die Kontrastierung zusätzlich erschwert: Vertrauen haben in, Angst haben vor. Ist hingegen eine Menge an FVG mit gleicher Präposition und vergleichbarer Bedeutung vorhanden, ist Kontrastbildung und demzufolge auch Extraktion problemlos möglich, vgl. etwa Angst, Respekt, Furcht, Ehrfurcht, Panik vor etwas haben.

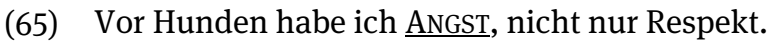

Im Fall von Hoffnung haben wird freilich z. B. durch ein quantifizierendes Pronomen eine Möglichkeit zur Kontrastbildung eröffnet, die dementsprechend auch die Extraktion der PP unproblematisch erscheinen lässt.

(66) Auf eine Verbesserung meiner Lage habe ich wEnig Hoffnung (vs. große Hoffnung, keine Hoffnung).

Die Ausnahmen in (56)-(58), die die Hypothese von der guten Extrahierbarkeit der PP aus FVG zunächst in Frage zu stellen scheinen, haben sich damit als erklärbar erwiesen: Die fehlende Möglichkeit der Extraktion beruht nicht darauf, dass hier eine der oben herausgearbeiteten Bedingungen nicht gegeben wäre, 
sondern resultiert schlicht daraus, dass hier kein Kontrast vorliegt und damit auch keine kontrastierende Topikposition besetzt werden kann.

Insgesamt ist auch im Problembereich PP-Extraktion deutlich geworden, dass für FVG keine konstruktionsspezifischen syntaktischen Regularitäten angenommen werden müssen. Soweit hier Elemente einer allgemeinen Theorie der PP-Extraktion skizziert werden konnten, reichen diese vollkommen aus, um das entsprechende Verhalten der FVG einzuordnen. ${ }^{158}$

\subsubsection{Mehrfache Vorfeldbesetzung}

Als Besonderheit von FVG des Deutschen hat Cook (2014) die Möglichkeit einer doppelten Vorfeldbesetzung beschrieben. Diese verstößt strenggenommen gegen die Regel, dass nur ein Satzglied im Vorfeld, d. h. in der Position links vom finiten Verb, erscheinen kann (Fanselow 1987: 99f.; St. Müller 2003: 30). Solche nichtkanonischen Formen der Vorfeldbesetzung zeigen die Beispiele in (67).

(67) a. [Weltweit] [für Aufregung] sorgt eine Werbekampagne von Benetton.

b. [Heftig] [in die Kritik] geriet der Kostenrechnungsbericht des Jugendamtes für 2002.

c. [Richtig] [Geld] wird nur im Briefgeschäft verdient.

(Cook 2014: 50f.)

Cook (2014: 51) analysiert die Kombinationen aus Modifizierer + PP/NP als „,collocational clusters“. Die Verben sorgen und geraten werden als „light verbs“ oder zumindest als „semi-light verbs“(Cook 2014: 54) behandelt (zu dem collocational cluster im engeren Sinne werden sie freilich nicht gerechnet). Cooks Auffassung von „light verb“ bzw. FVG orientiert sich dabei offenbar an einem allgemeinen Verständnis der Kategorie und wird deshalb auch nicht im Einzelnen ausgeführt.

Als Funktionsverbgefüge im Sinne dieser Arbeit sind die bei Cook (2014) genannten Verbindungen zwar nicht oder nur bedingt einzustufen. Gleichwohl kann es lohnend sein, Cooks Beobachtungen zum Zusammenhang von Vorfeldbesetzung und Verbkategorie auch auf FVG im hier vertretenen Sinne anzuwenden.

158 Auch Schmellentin (2006) nimmt in ihrem optimalitätstheoretischen Modell, das die Interaktion von syntaktischen, lexikalischen und informationsstrukturellen Faktoren bei der PP-Extraktion erklären soll, keine Sonderregeln für FVG an. 
Prüft man FVG, die dem Kriterium des implikativen Bedeutungsaufbaus entsprechen, im Hinblick auf eine doppelte Vorfeldbesetzung, so lassen sich in der Tat Fälle finden, in denen eine solche Besetzung im Wesentlichen akzeptabel ist, vgl. die Beispiele (68)-(71).

(68) a. Peter bringt seine Arbeit erfolgreich zum Abschluss.

b. [Erfolgreich] [zum Abschluss] bringt Peter seine Arbeit.

(69) a. Weltweit gibt die Kirche Antwort auf alle Fragen.

b. [Weltweit] [Antwort auf alle Fragen] gibt die Kirche.

(70) a. Ich habe nur vor Spinnen richtig Angst gehabt.

b. [Richtig] [Angst] habe ich nur vor Spinnen gehabt

(71) a. Der Richter fällt gnadenlos Urteile.

b. ?[Gnadenlos] [Urteile] fällt der Richter.

In (70a) liegt der Fall vor, dass die Konstituenten [richtig] und [Angst] auch im Mittelfeld adjazent vorkommen; dies wäre Cook (2014: 51) folgend als Argument für die Zusammengehörigkeit der beiden Konstituenten im Sinne eines ,modifiercollocational clusters“ zu werten. Für (70) sowie auch für Cooks Beispiel (67c) ist allerdings zu fragen, ob der Modifizierer [richtig] überhaupt ein Satzglied ist, ob hier also wirklich von mehrfacher Vorfeldbesetzung die Rede sein kann. Da [richtig] nach Ausweis von (72) nicht allein im Vorfeld stehen kann, ohne dass es eine adverbiale Lesart erzwingt oder doch sehr plausibel macht, liegt hier wohl auch gar keine mehrfache Vorfeldbesetzung vor.

(72) \#Richtig wird Geld nur im Briefgeschäft verdient.

Ein Urteil dazu, ob die Vorfeldbesetzungen in (68)-(71) akzeptabel sind oder nicht, mag vor allem für die Beispiele (69) und (71) unterschiedlich ausfallen. Entscheidend für die hier vorliegende Fragestellung ist aber lediglich, ob die doppelte Vorfeldbesetzung ein Kandidat für eine grammatische Besonderheit von FVG ist, wie im Anschluss an Cook (2014: 48) angenommen werden kann. Ein Blick auf Phraseologismen spricht indes gegen eine Annahme; vgl. zunächst (73) zu dem Phraseologismus jmdn. über den Tisch ziehen.

(73) a. Alle Bürger, die Steuern zahlen, zieht er in dreister Weise über den Tisch.

b. [In dreister Weise] [über den Tisch] zieht er alle Bürger, die Steuern zahlen. 
Die Möglichkeit der doppelten Vorfeldbesetzung bei Phraseologismen (die auch Cook 2014: 58 zumindest für Phraseologismen mit „light verb“ als gegeben voraussetzt) bestätigt die verbreitete Annahme, dass doppelte Vorfeldbesetzung mit einer engen Verbindung zwischen dem Verb und mindestens einer Konstituente des Vorfeldes einhergeht (vgl. auch Cook 2014: 51). Liegt nun freilich in (73) und ähnlichen Fällen eine enge Verbindung zwischen der PP [über den Tisch] und dem Verb vor, so stellt sich die Frage, ob man deshalb wirklich von zwei Vorfeldkonstituenten auszugehen hat. Fasst man bei Phraseologismen dieser Art PP und Verb als kollokative Einheit auf, ergibt sich die Möglichkeit einer Reanalyse: PP und Verb bilden hier gemeinsam gewissermaßen eine kollokative Quasi-Konstituente (zu dieser Auffassung Cook 2014: 53, 59 in Anlehnung an Beckner/Bybee 2009). Vor diesem Hintergrund stellt sich die vermeintlich irreguläre Besetzung des Vorfelds als weitgehend regelkonform dar, da dann mit dem Adverbial letztlich nur eine Konstituente ins Vorfeld bewegt wird. Ähnlich ließe sich auch für FVG argumentieren: Verb und PP/NP gehen eine enge Verbindung ein - was nicht zuletzt der oftmals mögliche Ersatz des FVG durch ein einfaches Verb belegt. Aufgrund der Zugehörigkeit der NP/PP zum finiten Verb nimmt diese dann auch keine Position im Vorfeld ein, weshalb der Topikalisierung einer anderen Komponente auch nichts im Wege steht.

Cooks Hypothese vom Zusammenhang zwischen kollokativen Strings und nicht-kanonischer Vorfeldbesetzung hat sich somit auch für FVG im Verständnis dieser Arbeit als fruchtbar erwiesen (hier allerdings lediglich auf die NomenVerb-Verbindung bezogen). Auf dieser Grundlage kann jedenfalls festgehalten werden, dass auch die doppelte Vorfeldbesetzung bei FVG keine konstruktionsspezifische Besonderheit darstellt, da hier allgemeine Erklärungen gefunden werden konnten.

Bevor freilich eine abschließende Beurteilung möglich ist, müsste die Regularitäten der mehrfachen Vorfeldbesetzung grundsätzlich besser verstanden werden. So stellt Eisenberg (2006a: 399) auch für nicht-idiomatische Kombinationen wie in dem Beispiel (74) fest: „Das Vorfeld kann auch mit mehreren Satzgliedern besetzt sein“.

(74) a. Irene hat ihm den Stern gezeigt.

b. [Ihm] [den Stern] gezeigt hat Irene.

Anzumerken ist auch, dass die Verbindung Modifizierer + PP/NP vorfeldfähig zu sein scheint, ohne dass diese mit einem FV kombiniert sein muss. Dies belegt $z$. B. das zumindest unter bestimmten Kontextbedingungen mögliche Beispiel (75a) 
mit dem Vollverb klopfen. Rückt die Kombination Modifizierer + PP/NP gemeinsam mit einem Partizip Perfekt ins Vorfeld, ist die mehrfache Vorfeldbesetzung offensichtlich noch leichter, wie (75b) zeigt.

(75) a. [Heftig] [gegen die Tür] klopft Peter, nicht Jan.

b. [Heftig] [gegen die Tür] geklopft hat PEter, nicht Jan.

Insgesamt sind die Bedingungen, unter denen eine mehrfache Vorfeldbesetzung akzeptabel ist, noch nicht ausreichend erforscht. Nach den hier angestellten Überlegungen dürfte aber sehr wahrscheinlich sein, dass FVG dabei keine Sonderrolle zukommt.

\subsection{Artikelgebrauch bei FVG}

\subsubsection{Eine Bestandsaufnahme}

Der Artikelgebrauch bei FVG stellt sich auf den ersten Blick kaum als regelhaft dar. Sowohl artikellose Nomina als auch Nomina mit bestimmtem oder unbestimmtem Artikel kommen vor, wie sich an den FVG in (76) zeigen lässt.

(76) a. Der Junge hat $\varnothing$ Hunger.

b. Das Mädchen gibt dem Jungen einen Stoß.

c. Er machte die Beobachtung, dass alle es sehr eilig hatten.

Bei FVG, die eine PP enthalten, tritt zudem Kontraktion des Artikels mit der voranstehenden Präposition auf:

(77) Peter brachte den Diebstahl zur Anzeige.

Da präpositionale FVG mit der Kontraktion von Präposition und Artikel eine Eigenschaft zeigen, die ausführlicher zu erörtern ist, sollen diese gesondert betrachtet werden. Zunächst ist auf den Artikelgebrauch der FVG mit einer NP im Akkusativ einzugehen, d. h. auf die Fügungen mit geben, machen, haben sowie finden. Um hier einen ersten Überblick über die Artikelsetzung zu erhalten, sollen die einzelnen FVG-Typen kurz vorgestellt werden; im Anschluss daran erfolgt eine zusammenfassende Auswertung. 


\subsubsection{1 geben-FVG}

Bei den FVG mit geben können je nach Kontext sowohl Nomina mit bestimmtem als auch solche mit unbestimmtem Artikel vorkommen. Teilweise kann das Nomen auch ohne Artikel gebraucht werden wie in (78d).

(78) a. Peter gibt uns eine Antwort.

b. Peter gibt uns die Antwort, die wir alle erwartet haben.

c. Peter gibt die Antwort, nicht Jonas. ${ }^{159}$

d. Peter gibt uns $\underline{\varnothing}$ Antwort

Bei den FVG mit geben, die dem Konzeptbereich ,Kommunikation' zuzuordnen sind, ist Artikellosigkeit wie in (78d) freilich nur auf einige wenige Beispiele beschränkt. Bei den geben-FVG, die dem Bereich ,Energietransfer zuzurechnen sind (der Typus einen Tritt geben, s. Kapitel 5.3.1), ist Artikellosigkeit nach Ausweis der Beispiele in (79) grundsätzlich nicht akzeptabel.

(79) a. Sie gab ihr einen Tritt/Kuss/Stoß.

b. *Sie gab ihr $\unrhd$ Tritt/Kuss/Stoß.

Bei den geben-Fügungen aus dem Bereich Kommunikation können, wie (80) zeigt, auch als Determinanten gebrauchte Possessivpronomina vorkommen.

(80) Seine Eltern gaben ihm die/ihre Erlaubnis zur Abreise.

\subsubsection{2 haben-FVG}

Bei den mit haben gebildeten FVG ist der Artikelgebrauch insofern ebenfalls relativ komplex, als auch hier unterschiedliche Konzeptklassen je eigene Muster aufweisen. So stehen Nomina in FVG, die eine Emotion bezeichnen (die also mit dem Verb empfinden kombinierbar sind), im Regelfall ohne Artikel.

(81) a. Das Mädchen hat $\varnothing$ Angst vor Gespenstern.

b. Der Junge hat $\varnothing$ Hunger.

159 Silben, die aus informationsstrukturellen Gründen akzentuiert sind, werden werden hier und im Folgenden in Kapitälchen gesetzt. 
Der unbestimmte Artikel kann - optional - nur dann gesetzt werden, wenn das Nomen mit einem Adjektivattribut steht. Ferner ist der unbestimmte Artikel auch im Exklamativsatz möglich.

(82) a. Das Mädchen hat (eine) riesige Angst.

b. Der Junge hat (eine) große Angst vor Gespenstern.

c. Das Mädchen HAT eine Angst/einen Hunger! (nur als Exklamativsatz)

Der bestimmte Artikel kann in diesen Fällen nicht vorliegen bzw. ist fraglich.

(83) a. *Peter hat die Angst vor Gespenstern.

b. ?Peter hat den Hunger.

Dieser Befund steht auch nicht im Widerspruch zu Beispielen wie (84), da hier eher von einem Demonstrativum als von einem Artikel auszugehen ist. Dies legt jedenfalls die Ersatzbarkeit von der/die/das durch eindeutig demonstratives dieser/diese/dieses nahe.

(84) Peter hat wieder die/diese Angst, die er als Kind schon hatte.

Während somit die haben-Fügungen aus dem Bereich Emotion tendenziell artikellos sind, ist der Artikel bei haben-FVG, die einen mentalen Zustand oder eine mentale Einstellung kodieren, obligatorisch:

(85) a. Niemand hat die Absicht, eine Mauer zu bauen.

b. Susi hat die Hoffnung, dass sich die Lage bessert.

c. Der Minister hat die Überzeugung, dass das Gesetz durchs Parlament kommt.

d. Ich habe den Eindruck, dass hier etwas schief läuft.

Die Gründe für das unterschiedliche Verhalten dieser beiden Untergruppen der haben-FVG (Emotion und mentale Einstellung) werden noch zu diskutieren sein.

\subsubsection{3 machen-FVG}

Die FVG mit machen zeigen nahezu durchgängig eine Präferenz des unbestimmten Artikels: 
(86) Peter macht eine Reise/einen Schritt/einen Salto/ein Kompliment/einen Versuch/eine Beobachtung.

Unter besonderen pragmatischen Bedingungen (Fokusposition) kann in diesen Fällen allerdings auch der bestimmte Artikel stehen:

(87) PEter macht die Reise, nicht sein Bruder.

\subsubsection{4 finden-FVG}

Hinsichtlich ihres Artikelgebrauchs sind hier auch die akkusativischen FVG mit finden zu nennen, die in dieser Untersuchung nur am Rande behandelt worden sind. Die Substantive dieser Verbindungen sind - zumindest im unmarkierten Fall - überwiegend artikellos (außer ein Ende finden, eine Erklärung finden).

(88) Der Vorschlag findet $\varnothing$ Anwendung/Bestätigung/Billigung/Berücksichtigung/Zustimmung/Nachahmung.

In Verbindung mit einem Attribut ist hingegen der bestimmte Artikel erforderlich.

(89) a. Der Vorschlag findet die verdiente Berücksichtigung.

b. Der Vorschlag findet die erhoffte Zustimmung.

c. Der Vorschlag findet die Zustimmung der Partei.

Auch der unbestimmte Artikel kann bei attribuiertem Nomen gesetzt werden: ${ }^{160}$

(90) a. Die Gründung des neuen Verbands Thurgauer Landwirtschaft fand eine breite Zustimmung. Zustimmung fand auch der jährliche Beitrag von maximal 2.50 Franken je Hektare für die bäuerliche Berufsbildung. (St. Galler Tagblatt, 17.03.2008, S. 22; Zugriff 06.04.2021)

b. Die Veranstaltung fand einen würdigen Abschluss.

160 Unter 100 Zufallsbelegen für Zustimmung finden in COSMAS II waren nur zwei Fälle mit unbestimmtem Artikel + Attribut (eine breite, eine gewisse Zustimmung finden; Zugriff 06.04.2021). 
Teilweise erscheint die Kombination unbestimmter Artikel + Attribut allerdings auch als fraglich:

(91) ?Der Vorschlag findet eine verdiente Berücksichtigung.

Insgesamt ist festzuhalten, dass der Artikelgebrauch der akkusativischen FVG als relativ heterogen gelten muss, wie die Tabelle 5 zusammenfassend zeigt.

Tab. 5: Artikelgebrauch bei FVG

\begin{tabular}{llll}
\hline & bestimmter Artikel & $\begin{array}{l}\text { unbestimmter } \\
\text { Artikel }\end{array}$ & Artikellosigkeit \\
\hline $\begin{array}{l}\text { geben-FVG } \\
\text { (KOMMUNIKATION) }\end{array}$ & $(+)$ & + & (im Einzelfall) \\
$\begin{array}{l}\text { geben-FVG } \\
\text { (ENERGIETRANSFER) }\end{array}$ & - & + & - \\
$\begin{array}{l}\text { haben-FVG } \\
\text { (EMOTION) }\end{array}$ & - & & + \\
$\begin{array}{l}\text { haben-FVG } \\
\text { (EINSTELLUNG) }\end{array}$ & + & $(+)$ & - \\
$\begin{array}{l}\text { machen-FVG } \\
\text { finden-FVG }\end{array}$ & $(+)$ & - & - \\
\hline
\end{tabular}

+ vorhanden

- nicht vorhanden

(+) unter bestimmten Bedingungen vorhanden, z. B. Attribuierung, Fokus

Dieser Befund kann zunächst dahingehend interpretiert werden, dass der Artikelgebrauch im Lexikoneintrag eines jeden FVG bzw. jeder FVG-Gruppe festgeschrieben ist (in diesem Sinne Fabricius-Hansen 2005: 425; Businger 2011: 242). Damit entfiele auch die Notwendigkeit einer (synchronen) Erklärung. Im Weiteren soll jedoch gezeigt werden, dass die auf den ersten Blick zufällig wirkende Artikelverwendung bei FVG mit den allgemeinen Regeln übereinstimmt und somit in weiten Teilen durchaus erklärbar ist. 


\subsubsection{Regeln des Artikelgebrauchs}

Für den Gegensatz von bestimmtem und unbestimmtem Artikel gilt nach der klassischen Auffassung in der Tradition von Russell (1905) (vgl. Kadmon 1990 und Hawkins 1991), dass sich der bestimmte und der unbestimmte Artikel durch die Eigenschaft der „uniqueness“ unterscheiden: Der bestimmte Artikel impliziert, dass es für die betreffende NP nur einen singulären Referenten gibt. Für (92a) ist daher Russell zufolge die Interpretation (92b) bzw. informell (92c) anzunehmen (Beispiel übersetzt aus Hawkins 1991: 406).

(92) a. Der Professor ist betrunken.

b. $\exists \mathrm{x}(\mathrm{P}(\mathrm{x}) \& \neg \exists \mathrm{y}(\mathrm{P}(\mathrm{y}) \& \mathrm{x} \neq \mathrm{y}) \& \mathrm{~B}(\mathrm{x}))$

c. Es gibt ein $\mathrm{x}$, das Professor ist, und es gibt kein $\mathrm{y}$, das Professor ist und nicht-identisch mit $\mathrm{x}$ ist, und $\mathrm{x}$ ist betrunken.

Der unbestimmte Artikel hingegen enthält keine Singularitätsbehauptung, (93a) wäre der Auffassung Russells folgend daher wie in (93b) bzw. (93c) zu beschreiben (vgl. Hawkins 1991: 407).

(93) a. Ein Professor ist betrunken.

b. $\exists \mathrm{x}(\mathrm{P}(\mathrm{x}) \& \mathrm{~B}(\mathrm{x}))$

c. Es gibt ein $\mathrm{x}$, das Professor ist, und $\mathrm{x}$ ist betrunken.

Die Äußerung (93a) ist dann wahr, wenn es mindestens einen Professor gibt, auf den die Eigenschaft „,betrunken“ zutrifft; sie ist aber auch dann wahr, wenn es mehrere Referenten dieser Art gibt. Die indefinite NP in (93a) trifft also keine Aussage über die Singularität ihres Referenten bzw. ist mit der Annahme, dass es mehrere entsprechende Referenten gibt, kompatibel. Diese NP ist dabei gleich in mehrfacher Hinsicht unbestimmt: Es kann mehrere Professoren geben, von denen nur einer betrunken ist, es kann aber auch angenommen werden, dass dies auf eine größere Teilmenge aus der Menge der Professoren zutrifft. (93a) ist sogar dann wahr, wenn alle Professoren betrunken sind.

Russells Analyse des Gegensatzes von Definitheit und Indefinitheit ist nicht ohne Widerspruch geblieben. Als prominenteste Alternativen sind Ansätze zu nennen, in denen anstelle der „uniqueness“ die Bekanntheit des Referenten im Diskursuniversum („familiarity“) zum zentralen Unterscheidungskriterium gemacht wird (vgl. hier vor allem die sog. „file-card-semantics“ von Heim 1982). Die Frage, ob die Eigenschaften „uniqueness“ und „Bekanntheit/Vorerwähnung im 
Diskurs“ sich in irgendeine Beziehung zueinander setzen lassen oder ob ein Konzept aus dem anderen hergeleitet werden kann, ist bislang noch nicht abschließend beantwortet (zu Versuchen einer Synthese vgl. u. a. Abbott 2005: 135-138; Schwarz 2009: 294). Im Weiteren wird vorwiegend der klassischen „uniqueness“Analyse der Vorzug gegenüber dem „familiarity“-Konzept gegeben. Dies ist nicht Ausdruck theoretischer Präferenz, sondern vor allem dem Umstand geschuldet, dass der Artikelgebrauch in FVG vielfach kontextunabhängig festgelegt ist und der Diskursverlauf nur eingeschränkte Bedeutung für die Wahl des Artikels besitzt (vgl. auch die Kritik von Hawkins 1991: 415 an dem Ansatz von Heim 1982).

\subsubsection{1 haben-FVG}

Was die hier interessierende Frage nach möglichen Bedingungen angeht, denen der Gebrauch des unbestimmten Artikels bei FVG gehorcht, sei zunächst auf die haben-Fügungen eingegangen; vgl. hierzu nochmals das Beispiel (82).

(82)’ a. Das Mädchen hat (eine) riesige Angst.

b. Der Junge hat (eine) große Angst vor Gespenstern.

c. Das Mädchen HAT eine Angst/einen Hunger! (nur als Exklamativsatz)

Das Attribut groß bzw. riesig qualifiziert den Zustand als stark ausgeprägt. Damit wird präsupponiert, dass es im Diskursuniversum eine Menge unterschiedlich starker Ausprägungen des Zustands Angst vor Gespenstern gibt, deren eine große Angst vor Gespenstern in (82) ist. Die Attribuierung der NP legt somit nahe, dass es nicht nur eine denkbare Angst gibt, sondern dass prinzipiell mehrere graduell unterschiedliche Ausprägungen des Gefühlszustandes anzunehmen sind. Die attribuierte NP kann aufgrund der Nicht-Singularität der Sachverhalte, die sie voraussetzt, auch mit dem unbestimmten Artikel verwendet werden.

In diesem Zusammenhang ist ferner die Frage $\mathrm{zu}$ beantworten, weshalb Angst, Hunger, Respekt haben im unmarkierten Fall ohne Artikel gebraucht werden. Artikellosigkeit eines Nomens ist im Regelfall ein syntaktisches Indiz dafür, dass es sich um ein Massenomen handelt (Krifka 1991: 413). In der Tat teilen Angst, Hunger und Respekt noch weitere syntaktische Merkmale mit prototypischen Massenomina wie Mehl oder Wasser, die sie zusammen mit diesen zugleich von zählbaren Nomina wie Haus oder Pferd abheben (vgl. Krifka 1991: 399). So sind die genannten Gefühlsbezeichnungen nicht bzw. nur bedingt pluralisierbar ( ̈̈ngste wäre eher als Arten- oder Sortenplural denn als ,echter' Plural zu interpretieren), und sie sind mit nicht-zählenden Quantoren viel, wenig oder ein bisschen verbindbar, während die Kombination mit Zahlwörtern nicht möglich ist; 
vgl. dazu die Gegenüberstellung von Gefühlsnomina in (94) und Massenomina in (95).

(94) a. * zwei Hunger, `zwei Respekt, \#zwei Ängste (nur als Sortenplural)

b. ein bisschen/viel/wenig Respekt, Hunger, Angst

(95) a. \#zwei Mehle, \#zwei Wasser (nur als Sortenplural)

b. ein bisschen/viel/wenig Mehl, Wasser

Auch wenn darüber diskutiert werden kann, ob es sich bei Ängste tatsächlich um einen Sortenplural handelt, ist eine durch die Parallelität von (94) und (95) suggerierte Nähe dieser Emotionsausdrücke zu Massenomina nicht von der Hand zu weisen. So sind die beiden zentralen semantischen Eigenschaften von Massenomina - Kumulativität und Homogenität (Quine 1960: 19; Krifka 1989: 39f.; Krifka 1991: 405f.; Jackendoff 1990: 29) - bei den genannten Emotionsausdrücken ebenfalls wiederzuerkennen:

- Kumulativität: Wenn zu Angst noch mehr Angst kommt, kann das Resultat ebenfalls als Angst bezeichnet werden (wie Mehl und noch mehr Mehl immer noch Mehl ergibt) (Quine 1960: 19),

- Homogenität: Angst, Hunger und Respekt sind nicht teilbar in Portionen, die selbst nicht als Angst, Hunger, Respekt zu gelten hätten.

Es ist zugegebenermaßen schwierig, Begriffe wie Kumulativität und Homogenität, die an konkreten Stoffnomina entwickelt wurden, auf abstrakte Entitäten wie Gefühle zu übertragen. Dennoch bleibt festzuhalten, dass Gefühlskonzepte wie die genannten mindestens aufgrund der Eigenschaften, die sie in (94) zeigen, prinzipiell als nicht zählbar zu gelten haben. Insofern tragen Gefühlsnomina Eigenschaften von Massenomina. Das Fehlen des unbestimmten Artikels in der unmarkierten Verwendung ist daher durchaus motiviert.

Bei einer zweiten Gruppe von FVG mit haben tritt im Regelfall der bestimmte Artikel auf, vgl. nochmals die Verbindungen in (85):

(85)' a. Niemand hat die Absicht, eine Mauer zu bauen.

b. Der Ministerin hat die Überzeugung, dass das Gesetz durch das Parlament kommt.

c. Ich habe den Eindruck, dass hier etwas schief läuft.

d. Susi hat die Hoffnung, dass sich die Lage bessert. 
Die Setzung des bestimmten Artikels hängt offensichtlich vom Vorhandensein eines Relativ- bzw. Infinitivsatzes ab, der vom Nomen regiert wird. Wenn, wie oben gezeigt, der bestimmte Artikel die Singularität des Referenten impliziert, ist gut erklärbar, weshalb nur der bestimmte, nicht der unbestimmte Artikel möglich ist. Der unbestimmte Artikel würde die Singularitätsannahme in Frage stellen, was mit unserem Weltwissen über mentale Zustände nicht vereinbar wäre - die Absicht z. B., etwas Bestimmtes zu tun, kann man nicht zur gleichen Zeit mehrfach haben. Daher ist die Setzung des unbestimmten Artikels nicht akzeptabel:

(96) a. *Niemand hat eine Absicht, eine Mauer zu bauen.

b. ^Die Ministerin hat eine Überzeugung, dass das Gesetz durchs Parlament kommt.

c. *Ich habe einen Eindruck, dass hier etwas schief läuft.

d. `Susi hat eine Hoffnung, dass sich die Lage bessert.

Dass Artikellosigkeit hier nicht auftritt, ist im Anschluss an das oben Dargelegte ebenfalls gut erklärbar. Absicht, Überzeugung und Eindruck bezeichnen zwar mentale Zustände und sind daher gut mit Angst, Respekt und Hunger zu vergleichen, die in FVG typischerweise artikellos auftreten. Im Unterschied zu diesen sind die Nomina in (96) jedoch, solange sie mit Attributsatz auftreten, nicht mit Quantoren wie wenig/viel/kaum verbindbar, die Nicht-Zählbarkeit indizieren, vgl. (97).
a. *viel Absicht, eine Mauer zu bauen
b. *viel Überzeugung, dass das Gesetz durchs Parlament kommt
c. *viel Eindruck, dass etwas schief läuft
d. wenig/?viel Hoffnung, dass sich die Lage bessert

Da Nicht-Zählbarkeit eine wichtige Voraussetzung für Artikellosigkeit ist, liegt es nahe, dass die Nomina Absicht, Überzeugung und Eindruck in (97a)-(97c) nicht ohne Artikel auftreten können und insofern von anderen nicht-zählbaren Nomina wie Angst, Hunger, Respekt abweichen. Dies wird auch dadurch untermauert, dass Absicht, Überzeugung und Eindruck im Gegensatz zu Hunger, Respekt und Angst (mit seinem Sortenplural Ängste) problemlos einen ,echten“ Plural bilden können. Der Zusammenhang zwischen Artikelsetzung und der Quantifizierbarkeit der NP wird auch durch (97d) bestätigt. Da gerade in diesem Fall ein nichtzählender Quantor wie wenig möglich ist, kann erwartungsgemäß auch Artikellosigkeit auftreten, vgl. (98). 
(98) Fraglich ist auch noch der Einsatz von Frank Baumann, der gegen Glasgow wegen einer Erkältung fehlte. „Ich habe Hoffnung, dass es geht“, sagte der Werder-Kapitän. (Braunschweiger Zeitung, 15.03. 2008; Zugriff 06.04.2021)

Rätsel geben freilich Verbindungen wie eine Abneigung gegen etwas/jmdn. sowie umgangssprachliches einen Hass auf etwas/jmdn. haben auf. Letzteres ist wahrscheinlich nur die drastischere Version des älteren eine Abneigung haben (vgl. ${ }^{2}$ DWB 1, 624); für die Umgangssprache wären solche Analogiebildungen jedenfalls nicht untypisch. Wenn man nur Abneigung betrachtet, zeigt dieses nach Ausweis von (99) durchaus Eigenschaften eines Massenomens.

(99) a. Viel/wenig Abneigung schlug ihm entgegen.

b. Voller Abneigung gegen Menschen suchte er die Einsamkeit.

Dass Abneigung im FVG nicht artikellos, sondern mit unbestimmtem Artikel auftritt, erscheint somit unmotiviert. Andererseits sind die Verbindungen viel Abneigung bzw. wenig Abneigung mit 8 Treffern und einem einzigen Treffer in DEREKo nicht eben häufig vertreten. Auch voller Abneigung ist mit 3 Treffern selten. Überdies kann Abneigung auch leicht in den Plural gesetzt werden, was für ein Massenomen wiederum nicht prototypisch ist. Eine Recherche in DEREKo ergibt immerhin 428 Treffer für Abneigungen wie z. B. (100).

(100) Die Vorlieben und Abneigungen beim Essen werden von klein auf geprägt. (St. Galler Tagblatt, 9.10.2010; Zugriff 06.04.2021).

Abneigung zeigt im Gegensatz zu Angst oder Respekt jedenfalls deutlich weniger ausgeprägte Eigenschaften eines Massenomens. Dies gilt erst recht für den antonymen Ausdruck eine Vorliebe (für etwas) haben, dessen Gefühlsnomen relativ deutlich nicht als Massenomen auftritt, wie (101) zeigt.

(101) a. *viel Vorliebe (drei Treffer in DeReKo, Zugriff 06.04.2021)

b. 'wenig Vorliebe (vierTreffer)

c. 'voller Vorliebe (ein Treffer)

In Bezug auf die haben-FVG kann somit das Fazit gezogen werden, dass der auf den ersten Blick unsystematisch erscheinende Artikelgebrauch sich insofern durchaus als regelhaft erwiesen hat, als in allen Fällen von der Semantik des je- 
weils vorliegenden Nomens bzw. der NP einschließlich ihrer Attribute auf die Artikelsetzung geschlossen werden konnte. Da die Semantik des Nomens bzw. der NP auch sonst ein Gesichtspunkt ist, der neben anderen (diskursbezogenen) Faktoren für die Artikelwahl ausschlaggebend ist, haftet der Artikelsetzung in habenFVG somit durchaus nichts Idiosynkratisches an.

\subsubsection{2 finden-FVG}

Mehrere Möglichkeiten des Artikelgebrauchs zeigen auch die FVG mit finden: In (102a) liegt Artikellosigkeit vor, in (102b) Artikellosigkeit in Kombination mit einem Attribut, in (102c) unbestimmter Artikel + Attribut und in (102d) schließlich bestimmter Artikel mit Attribut.

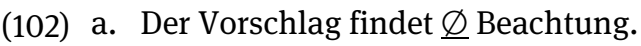

b. Der Vorschlag findet $\underline{\varnothing}$ große Beachtung.

c. Der Vorschlag findet eine große Beachtung.

d. Der Vorschlag findet die erhoffte Beachtung/die Beachtung des Vorsitzenden.

Der artikellose Gebrauch in (102a) und (102b) ist hier, wie bei den besprochenen haben-Fügungen, von der Bedeutung des Nomens her zu erklären. So kann $B e-$ achtung mittels viel/wenig quantifiziert werden; ferner handelt es sich um ein Singulare tantum. Aus diesen Gründen kann es als nicht-zählbar und somit prinzipiell artikellos gelten. Nichtzählbarkeit gilt auch für große Beachtung, auch wenn diese lediglich durch die mangelnde Pluralisierbarkeit, nicht aber durch den wenig/viel-Test erwiesen wird ('wenig/viel große Beachtung). Die Verbindung mit Attribut kann aber auch, wie in (102c), durch einen unbestimmten Artikel determiniert sein. Wie bereits in analoger Weise für (eine) große Angst haben dargelegt wurde, führt das Gradadjektiv die Annahme ein, dass es unterschiedlich starke Ausprägungen des durch die NP kodierten Sachverhalts gibt. Die im unmarkierten Fall gegebene Nichtzählbarkeit von Beachtung wird dadurch somit konterkariert: Es gibt zwar keine unterschiedlichen „Beachtungen“, jedoch durchaus unterschiedliche Grade von Beachtung, die hier präsupponiert sind. Dies rechtfertigt den Gebrauch des unbestimmten Artikels in (102c).

Der bestimmte Artikel bei Gradadjektiven ist hier allenfalls dann möglich, wenn ein Relativsatz folgt:

(103) a. *Der Vorschlag findet die große Beachtung.

b. Der Vorschlag findet die große Beachtung, die er verdient. 
Da der Vorschlag ein ganz bestimmtes Maß von Beachtung erhält, ist der Gebrauch des bestimmten Artikels als Ausdruck von Singularität motiviert: Es gibt im Fall von (103b) genau ein Maß von Beachtung (und zwar ein großes), das dem Vorschlag billigerweise zukommt. Aus diesem Grund sind auch die Fügungen in (104) regelgerecht:

(104) Der Artikel findet die verdiente/erhoffte/größtmögliche Beachtung.

Hier existiert lediglich eine Art der Beachtung, welche die durch das Adjektiv versprachlichten Qualitäten verdient/erhofft/größtmöglich aufweist. Im Unterschied zu Gradadjektiven wie groß oder breit werden in diesem Fall keine unterschiedlichen Ausprägungen von verdienter/erhoffter/größtmöglicher Beachtung präsupponiert. Der Artikelgebrauch erweist sich somit auch bei den finden-Fügungen FVG als durchweg erklärbar.

\subsubsection{3 machen- und geben-FVG}

Die FVG mit machen und geben fügen sich grundsätzlich in das bisher gezeichnete Bild ein. Handelt es sich bei den Substantiven um „count-nouns“ - sind diese also ohne Schwierigkeiten pluralisierbar und können sie nur mit zählenden Quantoren, nicht aber mit Quantoren wie viel/wenig gebraucht werden -, steht erwartungsgemäß der unbestimmte Artikel, vgl. die Fügungen in (105) und die entsprechenden Tests in (106).

(105) a. Einen Schritt, eine Reise, eine Bemerkung, eine Pause, einen Versuch machen

b. Einen Tritt, einen Befehl, eine Anordnung geben

(106) a. *viel Schritt/Reise

b. *viel Tritt/Befehl

Liegt hingegen (was seltener vorkommt) eine Lesart als Massenomen vor, ist erwartungsgemäß auch Nullartikel möglich:

(107) a. viel Urlaub, Ferien

b. Urlaub, Ferien machen

In Verbindung mit einem Attribut wie in (108) bzw. unter besonderen Kontextbedingungen wie in (109) kann alternativ auch der bestimmte Artikel gesetzt werden: 
(108) a. Peter gab ihm den Tritt, den er schon lange verdient hatte.

b. Peter gab ihm den Befehl, weiterzumarschieren.

c. Peter gab ihm die erwartete Antwort.

d. Susi machte die ersehnte Reise.

e. Susi machte den letzten Versuch.

(109) PEter gab ihm den Tritt, nicht Hans.

In (108) wird durch die Attribuierung des Nomens eine Singularitätsannahme eingeführt. Hier werden nicht mehrere erwartete Antworten, verdiente Tritte usw. vorausgesetzt, sondern genau ein Referent, auf den die entsprechende Eigenschaft zutrifft.

Erklärungsschwierigkeiten bereiten allerdings einzelne artikellose Formen. Bei den geben-FVG aus dem Bereich Kommunikation kann optional neben dem artikelhaltigen auch ein artikelloses Nomen vorkommen:

(110) a. Der General gab den $/ \varnothing$ Befehl, abzumarschieren.

b. Der General gab die/Ø Anweisung, alle Gefangenen freizulassen.

c. Peter gibt Antwort.

d. Peter gibt uns Aufklärung (?Peter gibt uns eine Aufklärung).

Während Aufklärung noch als Massenomen interpretierbar ist (viel/wenig Aufklärung), trifft dies auf Antwort und Befehl nicht zu (Antworten/Befehle, ?viel/wenig Antwort; *viel/wenig Befehl). Eine Erklärung für die optionale Artikellosigkeit in (110) steht also noch aus. (Möglicherweise sind die Fälle als Beispiele für die sog. Nominalinkorporation zu interpretieren, wie sie in artikellosem Auto fahren oder Klavier spielen vorliegt. Zur weiteren Diskussion dieser Frage sei auf Abschnitt 6.7 verwiesen.)

Bei den FVG mit machen gibt es ebenfalls erklärungsbedürftige Fälle mit artikellosem Nomen. So werden die Nomina in Jagd machen auf und Gebrauch machen von ganz überwiegend ohne Artikel verwendet (DEREKo hat lediglich vier Belege für eine Jagd machen gegenüber 5112 potentiellen Treffern für die entsprechende Verbindung ohne Artikel; Belege für einen Gebrauch machen konnten nicht ermittelt werden [Abfrage: 01.09.2011]).

(111) a. Der Polizist macht $\varnothing$ Jagd auf Diebe.

b. Der Polizist macht von seiner Waffe $\underline{\varnothing}$ Gebrauch. 
Um Massenomina handelt es sich bei Jagd und Gebrauch nicht (Jagden/Gebräuche, 'viel Jagd/'viel Gebrauch), daher ist das Fehlen des Artikels eigentlich nicht zu erwarten. Auffallend an den beiden FVG ist neben ihrer Artikellosigkeit auch die Tatsache, dass unter den machen-FVG nur diese beiden nicht pluralisierbar sind ( ${ }^{*}$ Jagden $/{ }^{*}$ Gebräuche machen). Es ist also möglich, z. B. (112a) zu formulieren, während ein entsprechendes (112b) oder (112c) nicht akzeptabel ist.

(112) a. Sie macht häufig Reisen nach Italien.

b. *Sie macht häufig Jagden auf Verbrecher.

c. `Sie macht häufig Gebräuche von ihrer Waffe.

Prinzipiell ist ein Plural zu Jagd und Gebrauch zwar bildbar; die Pluralformen weisen gegenüber dem Singular jedoch eigene semantische Spezifikationen auf; sie sind damit ansatzweise idiomatisiert: Für Gebräuche dominiert die Lesart ,Sitten, Bräuche‘, für Jagden überwiegt die konkrete ,weidmännische‘ Lesart. Pluralformen des Nomens sind in der für das FVG relevanten Lesart jedenfalls ungewöhnlich. Dies trifft besonders deutlich auf Gebräuche zu:
a. 'häufige Gebräuche von der Waffe
b. häufiger Gebrauch von der Waffe

Die Verbindung Jagden auf Verbrecher erscheint zwar möglich, sie ist aber alles andere als usuell: Im DEREKo ist sie ein einziges Mal belegt, eine google-Suche ergibt einige wenige Treffer, die aber deutlich die Assoziation ,brutale Jagd mit der Waffe' tragen ${ }^{161}$. Da es somit keine adäquaten Plurale für Jagd und Gebrauch in den entsprechenden FVG gibt, ist auch die Artikellosigkeit verständlich.

Sieht man von dem bislang schwer erklärbaren optionalen Nullartikel bei Antwort geben $\mathrm{u}$. ä. ab, kann für die akkusativischen FVG das Fazit gezogen werden, dass der Artikelgebrauch auf der Basis der Bedeutung des Nomens, vor allem seiner Zugehörigkeit zu den Kategorien nicht-zählbares vs. zählbares Nomen weitestgehend erklärbar ist. Die Artikel setzung bei akkusativischen FVG ist daher nicht als idiomatisch einzustufen, sondern entspricht grundsätzlich den allgemeinen Regularitäten.

161 Nur ,die vom US-Fernsehen gern gezeigten Jagden auf Verbrecher“ (Süddeutsche Zeitung, 24.03.2003; Zugriffe 06.04.2021). 


\subsubsection{Präpositionale FVG}

\subsubsection{Der Typus in Wut geraten}

Bei präpositionalen FVG erscheint der Artikelgebrauch auf den ersten Blick stärker eingeschränkt: „Die Funktionsverbgefüge wählen entweder eine Verschmelzung oder sie verzichten auf den Artikel“ (Fuhrhop 2007: 275). Hier kommen also im Wesentlichen die zwei Typen (114a) und (115a) vor, während andere Optionen ausgeschlossen oder nur sehr bedingt akzeptabel sind, vgl. (114b, c) und (115b):

(114) a. zur Anwendung bringen

b. 'zu der/einer Anwendung bringen

c. ${ }^{\star} \mathrm{zu} \unrhd$ Anwendung bringen

(115) a. in $\varnothing$ Aufregung sein

b. ?in der/einer Aufregung sein

In dieser Beschränkung auf Artikellosigkeit bzw. Artikelenklise sieht Fuhrhop sogar eine signifikante Eigenschaft präpositionaler FVG: „Dies unterscheidet die Präpositionalgruppe der Funktionsverbgefüge von anderen Präpositionalgruppen. Man kann es so beschreiben, dass die Substantive hier tendenziell artikellos erscheinen oder unflektiert oder infinit“ (2007: 275). Auch Eisenberg (2006b: 314f.) will in der Verschmelzung von Präposition und Artikel ausdrücklich eine definierende Eigenschaft von FVG erkennen (Eisenberg betrachtet lediglich Fügungen mit einer Präposition als FVG, s. Kapitel 2.3.2). Im Folgenden soll dafür argumentiert werden, dass Verschmelzung bzw. Nullartikel keine Eigenschaften sind, die FVG prinzipiell von anderen Präpositionalgruppen abheben oder gar klassenbildende Merkmale im Sinne Eisenbergs und Fuhrhops wären. Vielmehr soll hier - entsprechend den Darlegungen zu den akkusativischen FVG - gezeigt werden, dass die Kontraktion von Präposition und Artikel in (114) bzw. die Artikellosigkeit in (115) überwiegend auf allgemeine Gesetzmäßigkeiten des Artikelgebrauchs zurückgeführt werden können.

Am einfachsten ist die Regelhaftigkeit des Artikelgebrauchs bei präpositionalen FVG mit geraten zu zeigen, vgl. (116a), die teilweise auch ein Pendant mit sein aufweisen, vgl. (116b).

(116) a. in Aufregung, Hysterie, Abhängigkeit, Angst, Armut, Schwung, Bewegung, Wut geraten

b. in Aufregung, Angst, Schwung, Bewegung sein 
Alle in Frage kommenden Substantive zeigen insofern eine Eigenschaft von Massenomina, als sie den viel/wenig-Test passieren.

(117) viel/wenig Aufregung, Hysterie, Abhängigkeit, Angst, Armut, Bewegung, Schwung, Wut

Da Artikellosigkeit typisch für Massenomina ist, verhalten sich die FVG in (116a) somit erwartungsgemäß. Einen indirekten Beleg dafür liefert auch das FVG im Zweifel sein. Zweifel scheint zwar zunächst durchaus mit den Nomina in (117) vergleichbar zu sein; gerade in der Kombination mit viel/wenig verhält es sich jedoch anders als diese, da es nur mit wenig, nicht aber mit viel problemlos verbindbar ist; vgl. hierzu (118) gegenüber (119).

(118) a. 'Viel Zweifel kam auf. ${ }^{162}$

b. Wenig Zweifel kam auf.

c. Viele Zweifel waren geblieben.

(119) a. Viel Aufregung kam auf.

b. Das Vorhaben erzeugte wenig Aufregung.

c. \#Viele Aufregungen waren geblieben.

Da Zweifel zudem, wie (118c) belegt, problemlos im Plural auftreten kann, während Aufregung hierfür besondere Kontexte erfordert, ist es nicht als klares Massenomen einzuordnen. Dass gerade hier im Unterschied zu den Beispielen in (117) keine Artikellosigkeit vorliegt, ist somit erklärbar.

\subsubsection{Der Typus zur Anwendung kommen/bringen}

Die präpositionalen FVG mit kommen/bringen zeichnen sich generell durch die Kontraktion des Artikels mit der vorangehenden Präposition $z u$ aus. Dabei kann es sich um eine Idiosynkrasie handeln, die diese Gruppe von FVG systematisch von anderen Nomen-Verb-Syntagmen abhebt, wie Eisenberg (2006b) und Fuhrhop (2007) nahegelegt hatten (s. o.). Möglicherweise aber handelt es sich bei der hier durchgehend vorliegenden Kontraktion um eine Erscheinung, die sich - in ähnlicher Weise wie die Artikelsetzung bei den eben diskutierten Verbindungen

162 Eine COSMAS-Recherche ergab lediglich 104 Treffer für viel Zweifel, davon überwiegend so viel und zu viel. Für viele Zweifel wurden dagegen deutlich über 1000 Treffer ausgeworfen (Zugriff 06.04.2021). 
mit geraten/sein + in - von allgemeineren Regeln des Artikelgebrauchs her erklären lässt. Eine solche Erklärung hat auch Nübling (2005) vorgelegt. Sie stellt präpositionale FVG mit Artikelverschmelzung in eine unmittelbare Nachbarschaft zu präpositionalen Phraseologismen, die ebenfalls typischerweise mit kontrahiertem Artikel erscheinen, vgl. die Liste in (120).

(120) sich ins Bockshorn jagen lassen, am Hungertuch nagen, sich ins Fäustchen lachen, bis aufs Messer, ums Leben kommen, ins Hintertreffen geraten, jmdn. übers Ohr hauen, ans Ruder kommen, ins Gras beißen, ins Schwarze treffen, jmdn. hinters Licht führen, jmdn./etwas aufs Korn nehmen, ins Wasser fallen, im Dunkeln tappen, ins Reine bringen, sich über etwas im Klaren sein, jmdn. zum Narren halten ${ }^{163}$

Das Vorkommen kontrahierter Artikelformen sowohl bei Phraseologismen als auch bei FVG erklärt Nübling wie folgt:

Innerhalb von festen Wendungen jeglicher Art erfolgt beim Substantiv kein konkreter Bezug auf den genannten Referenten. Die Semantik aller Bestandteile verbindet sich zu einer neuen Gesamtbedeutung, die sich nicht aus der Summe der Einzelbedeutungen ableitet; die konkrete Vorstellung tritt zugunsten einer neuen, abstrakten Gesamtbedeutung zurück.

Nübling (2005: 110)

Der Bedeutungsverlust des Nomens wird somit für das Auftreten der obligatorischen Artikelverschmelzung verantwortlich gemacht. Die Phraseologismen in (120) wären demzufolge als „long words“ zu charakterisieren, deren interne Struktur opak geworden ist.

Nüblings Erklärung erscheint zwar plausibel; die von Nunberg/Sag/Wasow 1994) herausgearbeitete Tatsache, dass zahlreiche phraseologische Verbindungen existieren, denen sehr wohl ein gewisses Maß an Kompositionalität zugesprochen werden muss, die also nicht geradewegs als „long words“ gelten können, gibt indes Anlass zur Skepsis. Dass Nübling diese Erklärung ausdrücklich auch auf FVG des hier in Rede stehenden Typs zur Aufführung kommen/bringen bezieht, muss dabei als besonders problematisch gelten. Bei FVG kann gerade nicht davon die Rede sein, dass die Teilbedeutungen vollständig aufgegeben und

163 Enklise des Artikels ist nur dann möglich, wenn eine entsprechende Form zur Verfügung steht, d. h. wenn es sich um die Formen am, ans, aufs, beim, hinters, ins, im, übers, zum, zur handelt. Fügungen wie auf'n Hund kommen, in'ne Trinkhalle gehen sind daher in der Standardsprache nicht möglich. 
zu einer Gesamtbedeutung amalgamiert würden, welche nicht mehr auf ihre Bestandteile zurückgeführt werden könnte. Wie in Kapitel 3 gezeigt, kann die lexikalische Gesamtbedeutung eines FVG unmittelbar von der lexikalischen Bedeutung seines nominalen Bestandteils abgeleitet werden. Der Bedeutungsaufbau von FVG ist somit nicht mit dem der präpositionalen Phraseologismen in (120) vergleichbar, da hier etwa die NPs Bockshorn, Hungertuch oder Fäustchen keinen direkten Schluss auf die Gesamtbedeutung erlauben. Insofern ergibt sich von dieser Seite her keine Erklärung für den Artikelgebrauch bei FVG.

Um hier weiterzukommen, ist ein etwas differenzierterer Blick auf die Semantik von Definita vonnöten. Nach Hawkins (1978: 106-130) lässt sich die Kategorie Definitheit grundsätzlich in vier unterschiedliche Situationstypen untergliedern:

Tab. 6: Typen von Definitheit (nach Hawkins 1978; hier in Anlehnung an Schwarz 2009: 24).

\begin{tabular}{|c|c|}
\hline Situationstyp & Beispiel \\
\hline „immediate situation“ & $\begin{array}{l}\text { der Tisch (geäußert in einem Raum mit genau ei- } \\
\text { nem Tisch) }\end{array}$ \\
\hline „larger situation“ & die Bundeskanzlerin (geäußert in Deutschland) \\
\hline „anaphoric“ & $\begin{array}{l}\text { Hans kauft ein Buch und eine Zeitung. Das Buch } \\
\text { ist teuer. }\end{array}$ \\
\hline „associative anaphora“ & Hans kauft ein Buch. Der Autor ist Franzose. \\
\hline
\end{tabular}

Das mit unmittelbarem Situationsbezug verwendete Definitum kann Hawkins zufolge auch durch ein Demonstrativum ersetzt werden, vgl. (121); insofern kann man hier auch von deiktischem Gebrauch sprechen.

(121) Der/dieser Tisch wackelt.

Der „larger situation use“ kann sich zum einen auf Unikate wie die aktuelle Bundeskanzlerin (in Bezug auf Deutschland) beziehen. Ein solcher Gebrauch liegt aber auch in Fällen wie (122) vor:

(122) Peter geht in die Kneipe/ins Theater.

Die Äußerung (122) identifiziert keine einzelne Kneipe bzw. kein einzelnes Theater, sondern setzt lediglich voraus, dass innerhalb der „larger situation“ mindes- 
tens ein Referent existiert, auf den Kneipe/Theater zutrifft. Die beiden anaphorischen Gebräuche hingegen beziehen sich direkt bzw. indirekt auf ein im sprachlichen Kontext vorkommenden Antezedens, das explizit bzw. implizit bereits erwähnt wurde.

Besonders mit Bezug auf das Deutsche (einschließlich seiner Substandardvarietäten) ist wiederholt darauf aufmerksam gemacht worden, dass statt von einem einzigen Definitum besser von zwei definiten Artikeln - auch als „starker“ bzw. „schwacher Artikel“ bezeichnet - auszugehen ist (Krifka 1984: 28; Schwarz 2009: 12f.). Der starke Artikel entspricht Schwarz (2009: 9) zufolge den Gebrauchstypen Anapher bzw. assoziative Anapher, der schwache Artikel den beiden situationsbezogenen Gebräuchen („immediate“ bzw. „larger situation use“ in Hawkins' Klassifikation). Die Unterscheidung zwischen einem starken und einem schwachen Artikel wird in der genannten Forschungsliteratur nicht zuletzt durch das Vorhandensein der Artikelkontraktion im Deutschen plausibel gemacht. So ist Kontraktion von Präposition und Artikel grundsätzlich nur bei schwachem Artikel zu erwarten, d. h. dann, wenn situationsbezogener (oder unikaler) Gebrauch vorliegt; nicht-kontrahierte Formen sind in diesen Fällen ungrammatisch, vgl. (123):

(123) a. Ich bin im/*in dem Bad (= das eigene Bad).

b. Ich fliege heute zum Mond $/{ }^{\star} \mathrm{zu}$ dem Mond.

Schwarz (2009: 37-41) argumentiert, dass der schwache - d. h. der obligatorisch mit einer Präposition kontrahierte - Artikel auf „uniqueness“ im Sinne Russells verweist; der starke Artikel setze hingegen anaphorischen Gebrauch und damit Familiarität im Sinne Heims (1982) voraus, vgl. Schwarz (2009: 77). Eine ähnliche Unterscheidung trifft bereits Hartmann: „Vollformen des der-Artikels werden als anaphorische und deiktische Elemente [...] verwendet, Verschmelzungen in definiten Ausdrücken vor allem in nicht-anaphorischen Gebrauchsweisen“ (Hartmann 1980: 180).

Vor diesem Hintergrund wird klar, weshalb Vollformen des Artikels in FVG wie z. B. in (124) ungrammatisch sind.

^Peter bringt das Stück zu der Aufführung.

Wenn nicht-kontrahiertes zu der mit „starkem“ Artikel, wie oben dargelegt, grundsätzlich eine anaphorische Interpretation der definiten NP erzwingt, bedeutet dies, dass die Grammatikalität von (125) an die Vorerwähnung einer typischerweise indefiniten NP eine Aufführung gebunden wäre. Dies ist jedoch nicht 
der Fall. Eine Akzeptabilität unabhängig davon, ob ein Antezedens im Diskurs vorliegt oder nicht, kann nur die kontrahierte Form sicherstellen.

Interessant und erklärungsbedürftig ist in diesem Zusammenhang jedoch, dass (124) auch dann nicht als grammatisch einzuschätzen ist, wenn tatsächlich eine indefinite NP eine Aufführung im vorausgehenden Kontext auftritt, vgl. (125).

(125) Heute fand eine Aufführung des neuen Stücks statt. Der Autor selbst war es, der es zur $/{ }^{\star}$ zu der Aufführung brachte.

Die Artikelsetzung in (125) scheint damit im Widerspruch etwa zu der Äußerung in (126) zu stehen, in der ein im ersten Satz eingeführter Referent mit einem bestimmten Artikel (d. h. einem starken Artikel) im zweiten Satz wiederaufgenommen wird.

(126) a. Lisa liest in einem Buch. Ihr gefällt das Buch.

b. Peter geht zu einer Aufführung von Hamlet. Lisa kommt zu spät zu der Aufführung.

Der Grund dafür, dass zu der in (125) die FVG-Lesart aufhebt und der Satz damit ungrammatisch wird, kann darin gesehen werden, dass der starke Artikel zu der eine lokal-direktionale Lesart von Aufführung nahelegt. Zur Aufführung bringen in (125) wäre in diesem Fall nicht mehr als FVG identifizierbar. Damit liegt übrigens eine ähnliche Konstellation wie bei Phraseologismen mit einer PP vor. Auch hier führt der Ersatz eines schwachen Artikels zum Verlust der betreffenden Lesart bzw. zur Etablierung einer konkret-lokalen Interpretation (vgl. Eisenberg 2006a: 201; Schwarz 2009: 21):

(127) a. Der Apfel fällt nicht weit vom Stamm.

b. \#Der Apfel fällt nicht weit von dem Stamm.

Die Unterscheidung zwischen einem anaphorischen (starken) Artikel und einem nicht-anaphorischen, situationsbezogenen (schwachen) Artikel betrifft grundsätzlich nicht nur die Kombination von Präposition und reduziertem Artikel; auch der, die, das können nicht-anaphorisch und damit schwach sein (s. die Tabelle 6 mit der Übersicht zur Klassifikation von Hawkins 1978 sowie Krifka 1984: 28 und Schwarz 2009: 17f.). Die Differenzierung zweier Arten von Definitheit kann möglicherweise auch in einer anderen Frage weiterhelfen, die nicht unmittelbar hierher gehört, nämlich bei dem bislang noch ungelösten Problem des op- 
tional artikellosen Nomens in akkusativischen FVG des Typs Antwort geben/Befehl geben u. ä. (s. o. Kapitel 5.3). Hier ist neben dem unbestimmten Artikel auch Artikellosigkeit möglich, obwohl keine Massenomina vorliegen; vgl. dazu nochmals die Beispiele von oben:

(110)’ a. Der General gab den/ $\underline{\varnothing}$ Befehl, abzumarschieren.

b. Der General gab die/ $\varnothing$ Anweisung, alle Gefangenen freizulassen.

c. Peter gibt $\varnothing$ Antwort.

In den Fällen (110a)' und (110b)', in denen die Setzung des bestimmten Artikels optional ist, liegt ein schwacher, nicht-anaphorischer Artikel vor. Hier geht es, dem Modell von Schwarz (2009) entsprechend, um das Gegebensein von Singularität im Russellschen Sinne, nicht um Familiarität im Sinne Heims: Es gibt im Diskursuniversum nur einen Befehl, eine Antwort X. Es steht somit zu vermuten, dass der bestimmte Artikel hier deshalb weglassbar ist, weil er schwach ist. Liegt hingegen eine anaphorische Relation zwischen Artikel und vorangehendem Text vor, ist der starke Artikel (der im Gegensatz zum schwachen nicht weglassbar ist) die bessere Variante - in (128) ist der Fall allerdings etwas deutlicher als in (129):

(128) a. Die Soldaten marschierten ab. Der General gab den Befehl (dazu).

b. Die Soldaten marschierten ab. ?Der General gab $\varnothing$ Befehl (dazu).

(129) a. Niemand konnte zu der Frage etwas sagen. Dann gab Peter die Antwort.

b. Niemand konnte zu der Frage etwas sagen. ?'Dann gab Peter $\underline{\varnothing}$ Antwort.

Somit ergeben sich aus der Betrachtung der präpositionalen FVG im Nachhinein mögliche Aufschlüsse für einige problematische Fälle aus dem Bereich der akkusativischen Bildungen.

Wenn das Nichtvorkommen des anaphorischen Definitums bei präpositionalen FVG dieses Typs insgesamt motiviert erscheint, bleibt allerdings noch offen, weshalb der indefinite Artikel in den entsprechenden FVG nicht auftritt bzw. eine lokal-direktionale Interpretation der Nominalisierung erzwingt.

(130) a. \#Sie brachte das Stück zu einer Aufführung.

b. Sie brachte ihren Bruder zu einer Aufführung.

Dies verlangt umso nachdrücklicher nach einer Erklärung, als der unbestimmte Artikel bei FVG grundsätzlich nicht unüblich ist. Am konsequentesten zeigen die akkusativischen FVG des Typs einen Tritt geben den unbestimmten Artikel. Hier 
bietet sich als einfachste Erklärung wiederum an, die Artikelsetzung als im Lexikon festzuschreibende Eigenschaft der jeweiligen FVG zu behandeln. Dies ist allerdings nur dann zwingend, wenn keine Regularität gefunden werden kann, die die Artikelsetzung erklärt.

Wie zu Beginn des Kapitels gezeigt, führt der bestimmte Artikel die Annahme ein, dass der betreffende Referent singulär ist. Der unbestimmte Artikel ist hingegen mit der Annahme verbunden, dass es mehrere Referenten gibt, die mit dem betreffenden Nomen bezeichnet werden können. Auf die in Frage stehenden FVG übertragen hieße dies, dass die üblicherweise mit dem unbestimmten Artikel stehenden Nomina Tritt, Kuss, Schlag sich auf nicht-singuläre Sachverhalte beziehen müssten. Die Nomina Aufführung, Vollendung, Verteilung, Anwendung usw., die nicht mit dem unbestimmten Artikel stehen können, stünden dagegen für singuläre Sachverhalte. Dies soll im Folgenden als Arbeitshypothese diskutiert werden.

Betrachtet man die Ereignistypen, die in den jeweiligen FVG-Gruppen bzw. den dort vertretenen Nomina vorliegen, ergeben sich interessante Korrespondenzen zwischen Nominalsemantik und Artikelsetzung, die die zuletzt vorgebrachte Hypothese in der Tat untermauern. Die FVG des Typs einen Tritt geben bezeichnen durchgehend punktuelle Ereignisse ,treten', ,schlagen', ,küssen“ usw. Die einfachen Verben treten, schlagen, küssen sind dementsprechend ambig, da sie sowohl eine punktuelle als auch eine iterative Lesart besitzen (küssen zudem eine durative). Die präpositionalen FVG mit bringen hingegen versprachlichen grundsätzlich Accomplishments (s. o. Kapitel 5.2.5). Bei diesem Typ handelt es sich um endpunktorientierte Ereignisse, die eine komplexe interne Strukturierung aufweisen und die daher in der Regel auch eine Zeitspanne umfassen. Accomplishments zeichnen sich zudem sehr häufig dadurch aus, dass der Patiens nach Erreichen des Endzustandes „abgearbeitet“ ist. Bei diesem Ereignis liegen daher typischerweise nicht wiederholbare, singuläre Ereignisse vor, vgl. dazu die Beispiele in (131) gegenüber den punktuellen Ereignissen in (132).

(131) a. Der Architekt baut das Haus.

b. Das Mädchen isst den Apfel.

a. Das Mädchen tritt den Jungen.

b. Das Mädchen küsst den Jungen.

Ein Haus kann nur einmal gebaut, ein Apfel nur einmal gegessen werden. Die Ereignisse in (132) sind dagegen wiederholbar: Ein und derselbe Junge kann mehrmals von demselben Mädchen geküsst oder getreten werden. Vor diesem Hintergrund erscheint es naheliegend, dass FVG des Typs einen Tritt geben den 
unbestimmten Artikel fordern: Das Ereignis ,treten“ ist potentiell wiederholbar, es kann also eine Menge möglicher ,treten'-Ereignisse vorausgesetzt werden, weshalb der unbestimmte Artikel bei Tritt gesetzt werden muss. Aus diesem Grund ist hier auch das Nomen pluralisierbar (jmdm. viele Tritte geben).

Bei einer Vielzahl der präpositionalen FVG mit kommen/bringen liegt dagegen in der Tat ein Ereignis vor, nach dessen Abschluss der Patiens abgearbeitet ist und bei dem es sich folglich um ein singuläres Ereignis handelt:

(133) a. Er brachte den Dom zur Vollendung.

b. Er brachte das Bild zur Versteigerung.

c. Er brachte das Geld zur Verteilung.

Selbst wenn eine indefinite Objekt-NP einen Dom, ein Bild, eine Geldsumme vorliegt, kann das Ereignis einen identischen Referenten immer nur einmal, nie wiederholt betreffen.

Es gibt nun durchaus einzelne Accomplishments, bei denen eine Wiederholung des Ereignisses bei konstantem Referenten möglich erscheint. Das betrifft gerade den Musterfall ,aufführen“ bzw. das entsprechende FVG zur Aufführung kommen/bringen.

(134) Das Theater führt jeden Abend ,Tannhäuser‘ auf.

Allerdings ist jedem Sprecher bewusst, dass ,aufführen'-Ereignisse in der Regel nicht in einer unmittelbaren Folge ohne Pause wiederholbar werden wie etwa ,treten'- oder ,küssen'-Ereignisse. Von Iterativität kann daher hier nicht die Rede sein. Das Fehlen des unbestimmten Artikels (und natürlich auch die mangelnde Pluralisierbarkeit) können also auch in diesem Fall als motiviert gelten.

\subsubsection{Zwischenfazit}

Die Betrachtung akkusativischer und präpositionaler FVG hat gezeigt, dass der Artikelgebrauch im Wesentlichen von semantischen Eigenschaften des Nomens im FVG abhängt. Handelt es sich um ein Nomen, das Eigenschaften von Massenomina aufweist, ist, wie erwartbar, Artikellosigkeit vorherrschend. Zählbare Ereignisse hingegen treten im unmarkierten Fall mit unbestimmtem Artikel auf hier ist präsupponiert, dass es sich um einen Referenten aus einer Menge gleichartiger Referenten handelt (jmdm. einen Tritt geben, eine Antwort geben). Der be- 
stimmte Artikel wird bei FVG immer nur dann gebraucht, wenn besondere Bedingungen vorliegen, durch die ein singulärer Referent eingeführt wird (jmdm. den Tritt geben, den er verdient etc.). Für die präpositionalen FVG des Typs zur Aufführung kommen/bringen hat sich vor allem die Unterscheidung zwischen sog. starkem und schwachem Artikel als relevant erwiesen. Es konnte gezeigt werden, dass die mit der Präposition kontrahierte Form des Artikels - der sog. ,schwache“ Artikel - nur dann steht, wenn das im Nomen ausgedrückte Ereignis aufgrund seines Accomplishmentcharakters als singulär im Sinne Russels und damit nicht als anaphorisch $\mathrm{zu}$ interpretieren ist. Alles in allem hat sich der Artikelgebrauch bei FVG von sehr wenigen noch unerklärten Fügungen abgesehen als regulär erwiesen. Regeln, die auch sonst für den Artikelgebrauch angenommen werden, können ohne große Schwierigkeiten auf FVG übertragen werden. Die Artikelsetzung bei FVG gibt daher keinen Anlass, diese im Sinne der oben vorgestellten Positionen u. a. von Fuhrhop (2007) und Eisenberg (2006b) als eigene Klasse mit spezifischem grammatischen Verhalten anzusetzen.

\subsection{Attribuierung}

In engem Zusammenhang mit dem Artikelgebrauch sind auch die zu Beginn dieses Kapitels angesprochenen Einschränkungen bei der Attribuierung von Nomina in FVG zu sehen. Wie bereits die Beispiele im vorangehenden Abschnitt gezeigt haben, können FVG im Allgemeinen frei attribuiert werden. Eine Ausnahme bilden hier allerdings wiederum die zuletzt behandelten präpositionalen FVG des Typs zur Aufführung kommen/bringen, bei denen eine Attribuierung nicht bzw. nur sehr eingeschränkt akzeptabel ist, vgl. (135).

(135) a. 'Der Regisseur bringt das Stück zur aufwendigen Aufführung. ${ }^{164}$

b. 'Der Polizist bringt das Gesetz zur unbarmherzigen Anwendung.

c. \#Der Maler bringt sein Bild zur letzten Versteigerung.

d. ^Der Verlag bringt das Buch zum günstigen Druck.

164 Gelegentlich auftretende Attribuierungen bei zur Uraufführung kommen/bringen ändern nichts an diesem Bild. Auch in einem Beleg wie „Das Staatsorchester Rheinische Philharmonie bringt Vasks Komposition „Sala“ zur deutschen Uraufführung (Rhein Zeitung 14.02.2008, Zugriff 06.04.2021) ist die Singularität des Nominalereignisses Uraufführung gegeben, da es eben nur eine deutsche Uraufführung gibt. 
Gleiches gilt übrigens auch für vereinzelte präpositionale FVG mit anderen Verben, vgl. zum Druck geben in (136).

^Der Verleger gab das Buch zum günstigen Druck.

Da die Einschränkung der Attribuierungsmöglichkeit ganz überwiegend bei FVG mit einer PP und kontrahiertem/,schwachem' Artikel auftritt, erscheint ein Zusammenhang beider Erscheinungen naheliegend. Wie oben gezeigt, ist der Gebrauch des kontrahierten Artikels durch die Singularität (,uniqueness“) des jeweiligen Nominalereignisses motiviert. In dieser Singularität ist nun auch die Erklärung für die weitgehende Beschränkung der Attribuierungsmöglichkeiten bei dieser Gruppe von FVG zu sehen. Zieht man andere Verwendungen des schwachen Artikels wie z. B. die in (137) in Betracht, so zeigt sich auch hier, dass Attribuierungen mit besonderen Implikationen verbunden sind, wie (137b) gegenüber (137a) belegt.

(137) a. Er ging zum Auto und holte die Einkaufstasche aus dem Kofferraum.

b. Er ging zum/zu dem grünen Auto und holte die Einkaufstasche aus dem Kofferraum.

Der Satz (137a) mit schwachem Artikel und ohne Attribut wird in der Regel so interpretiert, dass in der betreffenden Kommunikationssituation nur ein einziges Auto relevant ist (es läge somit situationsgebundener Gebrauch im Sinne von Hawkins 1978 vor). Zu dem Auto anstelle von zum Auto würde hier einen aus dem Kontext bekannten Referenten Auto voraussetzen. Wird die PP wie in (137b) um ein Attribut erweitert, schlägt dies unmittelbar auf die Singularitätsannahme und damit auch auf den Artikelgebrauch durch: (137b) ist im Gegensatz zu (137a) so $\mathrm{zu}$ lesen, dass es im relevanten Kommunikationsbereich mindestens noch ein weiteres Auto gibt, auf das die Eigenschaft grün nicht zutrifft (und dementsprechend wird hier auch der starke Artikel verwendet, d. h. zum ist durch zu dem ersetzbar). Attribute - so kann man folgern - haben die Grundfunktion, Unterscheidungen zwischen verschiedenen Referenten zu treffen: Das eine Auto ist grün, das andere schwarz. Die Einführung eines Adjektivattributs ist somit mit der Annahme, das betreffende Ereignis sei singulär, nicht vereinbar. Da aber die FVG des Typs zur Aufführung kommen/bringen im Nomen ein Ereignis enthalten, das, wie oben gezeigt, aufgrund seiner Accomplishmenteigenschaften per se singulär ist, ist die Kombination des Nomens mit einem differenzierenden und damit Nicht-Singularität voraussetzenden Attribut nicht möglich. 
Interessant ist vor diesem Hintergrund allerdings das FVG zur Wirkung kommen. Im Unterschied zu der ganz überwiegenden Zahl der anderen FVG dieses Typs kann das Nomen hier sehr wohl mit einem Attribut, und zwar mit voll, verbunden werden, vgl. (138). ${ }^{165}$

(138) Erst jetzt kommen die Maßnahmen zur vollen Wirkung.

Dass hier eine Attribuierung möglich ist, steht indes nicht mit der Singularitätsannahme in Konflikt, da das Attribut voll hier von vornherein keine weiteren denkbaren Ausprägungen oder Grade des Ereignisses ,Wirkung‘ eröffnet. ${ }^{166}$ Andere Attribuierungen als mit voll sind in diesem FVG deshalb auch gar nicht erlaubt, vgl. gering in (139):

${ }^{\star}$ Die Maßnahmen kommen zur geringen Wirkung.

\subsection{Pluralisierbarkeit}

Was die Pluralisierbarkeit des Nomens in FVG betrifft, unterliegen vor allem zwei Gruppen von FVG deutlichen Einschränkungen. Zum einen fehlt bei den FVG des Typs zur Aufführung kommen/bringen, die ja auch im Hinblick auf Attribuierung und Artikelsetzung starke Restriktionen zeigen, die Möglichkeit einer Pluralbildung beim Nomen. Zum anderen bestehen auch beim haben-Typus diesbezüglich Einschränkungen. Dass bei bei zur Aufführung kommen/bringen u. dgl. keine Pluralsetzung möglich ist, erscheint vor dem Hintergrund des bisher Herausgearbeiteten aber geradezu zwingend: Wenn, wie oben dargelegt, die FVG des Typs zur Aufführung kommen/bringen mehrheitlich singuläre Ereignisse versprachlichen, ist es vollkommen konsequent, dass diese keinen Plural bilden können (vgl. Ehrich 1991: 443 mit weiterer Literatur). Spiegelbildlich gilt dann auch, dass FVG, die wiederholbare Ereignisse versprachlichen, problemlos mit einem Nomen im Plural erscheinen können. Dies ist bei den geben- und machen-FVG der Fall:

165 Eine COSMAS II-Abfrage nach der Kombination zur vollen Wirkung kommen ergab insgesamt 26 Treffer (Zugriff 06.04.2021); die Verbindung ist im Gegensatz zu voll zur Wirkung kommen (119 Treffer) als seltener einzustufen. Andere Adjektivattribute (z. B. * zur optimalen Wirkung kommen) ließen sich nicht belegen.

166 Eine COSMAS II-Abfrage nach der Kombination zur geringen bzw. halben Wirkung kommen ergab keinen Treffer (Zugriff 06.04.2021). 
(140) a. Befehle, Antworten, Anweisungen, Ratschläge, Tritte, Küsse, Ohrfeigen geben

b. Bemerkungen, Sprünge, Schritte, Versuche machen

Viele der haben-FVG erlauben allerdings keine Substantive im Plural. Bei den Fällen in (141) ist dies schlicht damit zu begründen, dass das Nomen auch außerhalb der FVG ganz überwiegend nur singularisch vorkommt.

(141) Furcht, Respekt, Durst, Hunger, den Glauben, Kummer, Langeweile, Mut, Panik, Spaß, Verdacht, Verständnis, Vertrauen, Wahn, Zutrauen

Umgekehrt gilt, dass Nomina, die in freier Verwendung meist oder ausschließlich im Plural erscheinen, auch im FVG pluralisch auftreten (Bedenken haben, Vorbehalte haben). In einigen Fällen, s. hier (142)-(145), kann allerdings auch dann, wenn grundsätzlich eine Pluralform des Nomens zur Verfügung steht, kein Gebrauch davon gemacht werden. Stattdessen ist nur das Nomen im Singular akzeptabel. Diese Fälle sind erklärungsbedürftig.

(142) a. Der Junge hat Angst vor dem Hund.

b. *Der Junge hat Ängste vor dem Hund.

(143) a. Das Mädchen hat die Absicht, Ärztin zu werden.

b. `Das Mädchen hat Absichten, Ärztin zu werden.

(144) a. Peter hat das Gefühl, dass etwas schiefläuft.

b. *Peter hat Gefühle, dass etwas schiefläuft.

(145) a. Das Mädchen hat die Gewissheit, dass alles gut läuft.

b. `Das Mädchen hat Gewissheiten, dass alles gut läuft.

Werden die Nomina ohne weitere Ergänzung, d. h. ohne PP oder Komplementsatz, verwendet, bestehen kaum Einschränkungen bei der Pluralisierbarkeit der Nomina, vgl. dazu (146).

(146) Der Junge hat Ängste/Absichten/Gefühle.

Der Gegensatz zwischen (142)-(145) auf der einen und (146) auf der anderen Seite erklärt sich allerdings recht einfach dadurch, dass mentale Zustände, die in irgendeiner Weise durch ein Attribut spezifiziert sind, nicht mehrmals auf einem identischen Experiencer bezogen werden können: Man kann nicht gleichzeitig 
verschiedene Absichten haben, nach Hause zu fahren. Fehlt eine solche Spezifizierung wie in (146), ist ein Plural sehr wohl möglich: Man kann sowohl die Angst vor Hunden als auch vor Gewitter haben usw.

Auffallend ist in diesem Zusammenhang allerdings, dass Pluralformen von Gefühlsnomina häufig insoweit eine besondere Konnotation aufweisen, als das betreffende Gefühl durch die Pluralsetzung als unbegründet, subjektiv oder gar irrational gekennzeichnet wird. ${ }^{167}$ Diese idiomatische Prägung der Pluralformen ist durchaus nicht auf FVG beschränkt, sondern gilt darüber hinaus:

(147) Aus europäischer Sicht mag man lächeln über die Ängste vieler Amerikaner vor dem „großen Staat“. (Mannheimer Morgen, 13.08.2009; Zugriff 06.04.2021)

(148) Auch Moskaus Patriarch bat den Herrn um Regen. Das Oberhaupt der Orthodoxie schraubte Hoffnungen auf baldigen Vollzug jedoch gleich herunter. (St. Galler Tagblatt, 06.08.2010; Zugriff 06.04.2021)

Im Gegensatz zu den Beispielen (142)-(145) ist bei FVG mit diesen Nomina die Kombination von Pluralsetzung und Attribuierung (in diesem Fall eine angeschlossene PP bzw. ein Relativsatz) durchaus im Rahmen des Möglichen, vgl. (149) und (150).

(149) Viele Schüler haben Ängste vor dem Französischen, weil dieser Sprache der Ruf vorauseilt, „besonders schwer“ zu sein. (Nürnberger Zeitung, 10.04.2010; Zugriff 06.04.2021)

(150) „Die Kommission hatte Befürchtungen, es sei ein Begünstigungsgesetz für die Deutsche Telekom. Diese Befürchtung ist unbegründet [...]“, sagte Glos gestern. (Braunschweiger Zeitung, 12.06.2006; Zugriff 06.04. 2021)

Da die Nomina Ängste/Befürchtungen hier nicht eine Menge unterschiedlicher mentaler Zustände beschreiben, sondern der Plural nur auf die Subjektivität des jeweiligen Zustandes zielt, ist, anders als in (142)-(145), eine Erweiterung durch ein Attribut, das diesen einen Zustand näher beschreibt, unproblematisch.

167 Auch in Nöten sein zeigt ansatzweise eine Idiomatisierung des Plurals. Es liegt weniger eine ,schlimme Lage, aus der jemand dringend Hilfe braucht‘ vor, sondern eher ein ,Gefühl der Not' (zur Unterscheidung s. DUW 1145). 


\subsection{Negation}

FVG, die eine Präpositionalgruppe enthalten, zeichnen sich auch durch eine Auffälligkeit bei der Negation aus. Diese besteht darin, dass Fügungen des Typs in Wut geraten und zur Aufführung bringen hinsichtlich ihrer Grammatikalität deutlich besser zu bewerten sind, wenn sie mit nicht negiert werden, während Negation mittels kein demgegenüber fragwürdig ist; vgl. dazu die Beispiele in (151)(152).

(151) a. Er brachte den Kuchen nicht zur Verteilung.

b. 'Er brachte den Kuchen zu keiner Verteilung.

(152) a. Sie ist nicht in Wut geraten.

b. 'Sie ist in keine Wut geraten.

Daher beschreibt Fabricius-Hansen (2005: 425) das Negationsverhalten präpositionaler FVG auch als klassenspezifische Eigenheit (vgl. Hentschel/Weydt 2003: 86; Businger 2011: 243). Vor dem Hintergrund der oben herausgearbeiteten semantischen Eigenschaften des Nomens ist dieses Negationsverhalten allerdings wenig überraschend. Eine Negation mittels kein, das ja die Verneinung des unbestimmten Artikels ist (nicht ein), würde voraussetzen, dass es eine Menge von Alternativereignissen gäbe, aus welcher in der Prädikation dann eines herausgegriffen würde. Dies ist jedoch, wie oben gezeigt, nicht der Fall, da es sich bei den Ereignisnomina um Accomplishments handelt, die grundsätzlich singulär sind. Die Negationseigenschaften dieser Gruppe von FVG ergeben sich somit wiederum unmittelbar aus semantischen Eigenschaften der Nomina und müssen nicht als Besonderheiten oder gar Definitionskriterien von FVG (wie bei Businger 2011: 243 der Fall) festgehalten werden.

FVG des Typs in Wut geraten zeigen nach Ausweis von (152) dasselbe Negationsverhalten wie die eben besprochenen Verbindungen. Das Fehlen von kein ist auch hier von der Bedeutung des Nomens her zu begründen, freilich in etwas anderer Weise. Dass die kein-Negation nicht möglich ist, hängt damit zusammen, dass die Gefühlsnomina, die bei diesen FVG dominieren, Eigenschaften von Massenomina aufweisen (s. o. Kapitel 6.3.3). Auch Massenomina sind nicht ohne Weiteres mit kein negierbar; hier wird eher nicht vorgezogen, während kein besondere Kontexte erfordert, wie die Beispiele (153b) und (154b) belegen.

(153) a. Die Sardinen sind nicht in Öl eingelegt.

b. \#Die Sardinen sind in kein(em) Öl eingelegt. 
(154) a. Ich habe meine Hand nicht ins Wasser getaucht.

b. \#Ich habe meine Hand in kein Wasser getaucht.

Die Verbindung von kein mit einem Massenomen wie in (153) und (154) erzwingt die Annahme, dass verschiedene Sorten oder Arten von Öle bzw. Wasser zur Auswahl bereitstehen. Bei Gefühlsnomina ist eine solche Verfügbarkeit von Alternativen ausgeschlossen - wenn man in Wut oder Aufregung gerät, gibt es im Hintergrund nicht noch eine andere ,Sorte' desselben Gefühls, in das man verfallen könnte.

\subsection{Objektinkorporation}

Hinsichtlich ihrer syntaktischen Struktur werden FVG häufig in einen Zusammenhang mit Nomen-Verb-Syntagmen gestellt, die sog. „Objektinkorporation“ aufweisen (Grewendorf 1989: 46; Gallmann/Sitta 1992: 160f.; Gallmann 1999: 283f.; Dürscheid 1999: 29f.; Winhart 2005: 34, 193). Es handelt sich dabei um Verbindungen wie in (155).

(155) a. Auto/Bahn/Boot/Bus/Fahrrad fahren, radfahren

b. Klavier/Cello/Karten spielen

c. Ski/Rollschuh/Schlittschuh laufen, Eis laufen

d. Schlange stehen/Kopf stehen/Maschine schreiben/Dank sagen/Zeitung lesen

Der überwiegend an außereuropäischen Sprachen entwickelte Begriff der Inkorporation bezeichnet ein Wortbildungsphänomen, bei dem ein in der Regel frei vorkommender Wortstamm mit einem Verb komponiert wird und beide ein morphologisch komplexes Verb ergeben (vgl. Mithun 2000: 916). ${ }^{168}$ Die inkorporierten Nomina besind im Gegensatz zu freien Nomina nicht referentiell. Dies zeigt sich daran, dass sie keine Numerus- bzw. Kasusmarkierung aufweisen, nicht durch Artikelwörter bestimmt oder durch Attribute erweitert werden können und

$168 \mathrm{Im}$ Gegensatz zur sprachtypologisch ausgerichteten Literatur, die überwiegend von einem morphologischen Prozess ausgeht, beschreibt Baker (1988) Inkorporation als syntaktische Bewegungsoperation. Zu den Problemen, die Bakers syntaktische Inkorporationstheorie für die Daten des Deutschen aufwirft, vgl. Pittner (1998: 110f.). 
auch nicht erfragbar oder pronominalisierbar sind (vgl. Bausewein 1990: 62-65; Pittner 1998: 107). ${ }^{169}$

(156) a. *Sie fährt altes Auto.

b. 'Sie fährt Auto mit Spoiler.

c. * Sie fährt Auto, das direkt aus der Werkstatt kommt.

d. Sie fährt Auto. ?Sie hat es in die Werkstatt gebracht.

Als Charakteristikum von Objektinkorporation wird auch die Existenz syntaktischer Parallelen genannt, in denen das entsprechende Nomen mit voller Referentialität auftritt. Die referentiellen Entsprechungen können auch als die zugrundeliegenden Strukturen betrachtet werden, auf denen die Verbindungen mit Inkorporation beruhen (Bausewein 1990: 63-65); vgl. dazu jeweils die Beispiele (157b) und (158b).

(157) a. Er liest Zeitung. (Inkorporation)

b. Er liest die Zeitung. (keine Inkorporation)

(158) a. Sie fährt Auto. (Inkorporation)

b. Sie fährt mit dem Auto. (keine Inkorporation)

Da die Nomina in FVG zum Teil ebenfalls die für Inkorporation charakteristischen Eigenschaften zeigen - potentielle Artikellosigkeit, fehlende Attribuierung, keine Pluralbildung, fehlende Pronominalisierbarkeit -, ist in der Tat zu erwägen, ob nicht möglicherweise auch bei FVG zumindest partiell Objektinkorporation vorliegt.

Ein Zusammenhang zwischen Nominalinkorporation und FVG ist überwiegend für präpositionale FVG (Gallmann 1999: 292-294; Winhart 2005: 34, 193), seltener auch für akkusativische FVG (Dürscheid 1999: 29f.) behauptet worden.

169 Als Untertyp der Inkorporation wird häufig das sog. „Noun-Stripping“ behandelt (vgl. Mithun 2000: 920 mit weiterer Literatur). Hierbei bleibt das Nomen als phonologisch eigenständige Einheit erhalten, lediglich die flexivischen Merkmale des Nomens werden ,abgestreift'. Inwiefern bei den Erscheinungen in (157) Inkorporation im engeren Sinne oder Noun-Stripping vorliegt, kann hier nicht erörtert werden. Gallmann (1999: 299) nimmt an, dass Fälle wie in (157) im Deutschen als Noun-Stripping aufzufassen seien, da es sich um eigenständige syntaktische Wörter handle, die überwiegend als Kopfadjunkte zu beschreiben seien. Folgt man der von Mithun (2000: 961) vorgeschlagenen Definition (s. o.), der zufolge die phonologische Eigenständigkeit ausschlaggebend ist, käme für das Deutsche auch Inkorporation im engeren Sinne in Betracht, da die Bildungen in (140) offenbar eine Akzenteinheit darstellen ('Auto fahren vs. 'Auto 'fahren). 
Zunächst zu den akkusativischen FVG. Die Möglichkeit der Artikellosigkeit tritt hier in den folgenden Beispielen auf:

(159) a. Berücksichtigung/Billigung/Anerkennung finden

b. Kritik/Verrat/Zurückhaltung üben

c. Lob/Anerkennung zollen

d. Ersatz/Folge/Gehorsam/Verzicht/Widerstand leisten

e. Angst/Hoffnung haben

f. Antwort/Anweisung geben

Ein Zusammenhang zwischen beiden Typen von Nomen-Verb-Verbindungen erscheint somit auf den ersten Blick naheliegend. Was die für Inkorporation signifikante Nichtattribuierbarkeit bzw. Nichtpronominalisierbarkeit des artikellosen Nomens angeht, zeigt allerdings schon ein erster Testdurchlauf, dass akkusativische FVG den genannten Kriterien für Objektinkorporation nicht durchweg genügen, vgl. hier beispielhaft die Fälle in (160).

(160) a. Der Vorschlag fand die Berücksichtigung, die ihm gebührte.

b. Er übte Kritik. Sie war sehr hart.

c. Er leistete erbitterten Widerstand.

Allenfalls Antwort geben und Folge leisten zeigen insofern Eigenschaften von Inkorporation, als Adjektivattribute und Pronominalisierungen nur partiell möglich sind.

(161) a. Antwort geben

b. ${ }^{\star}$ Er gab gute Antwort.

c. Er gab Antwort. ${ }^{\star}$ Sie war gut.

(162) a. Folge leisten

b. 'Er leistete willige Folge.

c. Er leistete Folge. ${ }^{\star}$ Sie war willig.

Bei artikellosem Antwort geben in (161) ist jedoch immerhin ein präpositionales Attribut auf + NP möglich. Läge Objektinkorporation vor, wäre dies ausgeschlossen, da inkorporierte Nomina grundsätzlich nicht erweiterbar sind. 
(163) Die Studie liegt nun vor und gibt Antwort auf die Fragen nach der Verkehrsqualität. (St. Galler Tagblatt, 19.05.2010, S. 35; Zugriff 06.04.2021)

In den anderen Fällen besteht gleichfalls die Möglichkeit einer Attribuierung durch Adjektive bzw. präpositionale Phrasen, auch wenn auffällt, dass bei den Adjektivattributen häufig nur eine eingeschränkte Variationsbreite gegeben ist und vielfach ein Kollokationsverhältnis zwischen Nomen und Adjektiv zu existieren scheint: scharfe, harsche Kritik üben; vornehme Zurückhaltung üben; erbitterten, heftigen Widerstand leisten.

Es bleibt folglich festzuhalten, dass von der Artikellosigkeit der hier behandelten akkusativischen FVG in (161)-(162) nicht auf fehlende Referentialität und damit auf eine Parallelität zum Phänomen der Objektinkorporation geschlossen werden kann. Die verbreitete Möglichkeit einer Attribuierung und Pronominalisierung lässt vielmehr durchaus auf die Referenzfähigkeit der betreffenden Nomina schließen. Wenn Artikellosigkeit bei akkusativischen FVG auftritt, so ist sie nicht durch ein besonderes Phänomen wie Objektinkorporation, sondern schlicht von der Semantik des Nomens her zu erklären (s. o. Kapitel 6.3).

Stärkere Übereinstimmung mit der Objektinkorporation zeigen die präpositionalen FVG des Typs zur Aufführung kommen/bringen, da sie weder attribuierbar noch pronominalisierbar noch erfragbar sind.

(164) a. „Hamlet“ kommt zur Aufführung.

b. ?Hamlet“ kommt zur gelungenen Aufführung.

c. \#,Hamlet“ kommt zu einer Aufführung.

d. „Hamlet“ kam zur Aufführung. ?Sie war gelungen.

e. „Hamlet“ kommt zur Aufführung. - *Wozu kommt „Hamlet“?

Dass keine Attribuierung möglich ist, lässt sich jedoch, wie in Abschnitt 6.4 ausgeführt, von der Semantik des Ereignisnomens her motivieren: Es handelt sich um ein singuläres Ereignis, das deshalb auch nicht gegenüber anderen Ereignissen durch ein Attribut differenziert werden kann und dementsprechend einen schwachen Artikel (im Sinne von Abschnitt 6.3.2) trägt.

Die mangelnde Pronominalisierung von FVG ist freilich anders zu erklären, da der schwache Artikel grundsätzlich eine pronominale Wiederaufnahme bzw. Erfragung zulässt, vgl. (165)-(166):

(165) a. Ich ging zum Auto. Es war ganz eingeschneit/Es sprang nicht an.

b. Ich ging ins Restaurant. Es war geschlossen. 
(166) Wohin bist du gegangen? - Ich bin zum Auto gegangen.

Die Unmöglichkeit einer pronominalen Wiederaufnahme erscheint umso überraschender, als diese Einschränkung nur für den genannten FVG-Typus gilt. Andere FVG zeigen durchaus pronominale Wiederaufnahme des Nomens, vgl. (167).

(167) a. Susi gab ihrer Schwester einen Kuss. Er war sehr herzlich.

b. Der Mann machte eine Bewegung. Die verriet ihn.

Wie im Abschnitt 6.4 dargelegt, hängt die mangelnde Möglichkeit der Wiederaufnahme des Nomens in (164d) mit dessen Accomplishmentcharakter zusammen, durch den eine Singularitätsannahme für das Ereignis eingeführt wird. Wegen der Singularität des Ereignisses ist ein Folgesatz, in dem das Ereignis näher bestimmt wird, ebenso wenig sinnvoll wie ein Attribut: Indem man eine Eigenschaft für einen Referenten einführt, wird dieser zugleich von anderen Referenten abgegrenzt; gibt es aber von vornherein nur einen einzigen Referenten im Diskursuniversum, erübrigt sich eine solche Abgrenzung. Dass die Nomina in (167) dagegen ohne Schwierigkeiten in einem Pronomen wiederaufgenommen werden können, ist vor diesem Hintergrund einleuchtend, handelt es sich hier ja gerade um potentiell wiederholbare Ereignisse.

Die fehlende Möglichkeit, das FVG in (164e) zu erfragen, ist anders motiviert. Hier liegt es schlicht daran, dass das Fragepronomen wozu auf eine geschlossene Klasse von Lesarten festgelegt ist: Es ist primär final (Wozu dient das?), und würde damit auch der erfragten PP zur Aufführung eine finale Interpretation aufzwingen. Aus diesem Grund kann das Nomen in (164e) nicht erfragt werden.

Als Argument für das Vorliegen von Objektinkorporation bei FVG taugen somit weder die fehlende Erfragbarkeit noch die mangelnde Wiederaufnahme. Dass Objektinkorporation auch darüberhinausgehend nicht mit FVG vergleichbar sind, zeigt sich jedoch in aller Deutlichkeit, wenn man den besonderen Bedeutungsgehalt berücksichtigt, der Verbindungen mit Inkorporation im Regelfall eigen ist. So weist Pittner (1998: 110) darauf hin, dass die Inkorporation „ein einheitliches Konzept kennzeichnet und dazu tendiert, habituelle, permanente oder charakteristische Aktivitäten und Ereignisse zu bezeichnen“ (vgl. auch Mithun 2000: 917: „they [inkorporierte Nomina, V. H.] appear in verbs describing habitual or generic activities rather than for particular events involving specific patients“). Eine Einschränkung auf habituelle bzw. permanente Aktivitäten und Ereignisse zeigen FVG indes nicht. Der immer wieder hergestellte Zusammenhang zwischen FVG und Verbindungen mit Objektinkorporation erweist sich somit insgesamt als wenig erhellend. 


\subsection{Fazit}

Für die Syntax von FVG des Deutschen lässt sich zusammenfassend konstatieren, dass diese lediglich in einem Punkt von regulären syntaktischen Strukturen abweicht, nämlich im Hinblick auf die Zuweisung der Argumente. Das FVG vergibt hier offenbar als Ganzes seine Argumente und ist insofern mit idiomatischen VP wie jmdn. übers Ohr hauen vergleichbar. Bei näherem Hinsehen erweist sich dies freilich als wenig überraschend: Das FV scheint selbst nicht in der Lage zu sein, Argumente zu vergeben, und übernimmt daher die entsprechenden Positionen vom Ereignisnomen; lediglich die Kasuszuweisung erfolgt über das Verb selbst. Die Annahme eines solchen Argumenttransfers, wie ihn Grimshaw/Mester (1988) und Culicover/Jackendoff (2005: 222f.) vertreten haben, ist Ansätzen, die die Argumente als Attribute zum Nomen im FVG analysieren, überlegen, da Letztere die Daten nicht vollständig zu erklären vermögen. Die Argumenttransfer-Hypothese hat lediglich den Nachteil, dass ein eigener Lexikoneintrag für das FV stipuliert werden muss, der vom Lexikoneintrag des Vollverbs zu unterscheiden ist; diese doppelten Einträge sind in diesem Ansatz nötig, da die Tatsache, dass FV nur einen Kasus, aber keine Rollen zuweisen, nicht auf andere Weise erklärt werden kann. Für das Problem eines zweifachen Lexikoneintrags sei aber auf die Ausführungen im übernächsten Kapitel verwiesen.

Die enge Zusammengehörigkeit von FV und NP bzw. PP hat in der Forschung auch Anlass gegeben, FVG als Fälle von Objektinkorporation zu behandeln, wie sie bei Konstruktionen wie Flöte spielen oder Auto fahren vorliegt. Die semantischen Unterschiede zwischen den Konstruktionstypen FVG und Objektinkorporation sind jedoch insgesamt zu groß, als dass sich FVG hier nahtlos einfügen ließen. Verbindungen wie Flöte spielen oder Auto fahren unterliegen zudem bei der Attribuierung und der pronominalen Wiederaufnahme wesentlich strikteren Restriktionen, als sie für FVG gelten. Die These, es läge auch bei FVG Objektinkorporation vor, bietet somit keinen Erkenntnisgewinn.

Was die anderen hier untersuchten (morpho)syntaktischen Eigenschaften Wortstellung, Artikelsetzung, Attribuierung, Pluralisierbarkeit, Negation - betrifft, konnte gezeigt werden, dass das auf den ersten Blick idiosynkratisch anmutende Verhalten von FVG durchweg erklärbar ist. Sehr viele der betreffenden Erscheinungen ließen sich von semantischen Eigenschaften des jeweiligen Ereignisnomens her begründen bzw. auf allgemein gültige Mechanismen zurückführen. FVG haben sich damit gegen eine verbreitete Auffassung als syntaktisch weitestgehend regulär erwiesen. Konstruktionsspezifische (morpho-) syntaktische Eigenschaften sind für FVG folglich nicht anzunehmen. Was dies für die Modellierung von FVG im Sprachsystem bedeutet, wird in Kapitel 8 erörtert. 